\title{
Experts in the crowd and their influence on herding in reward-based crowdfunding of cultural projects
}

\author{
Aurélien Petit - Peter Wirtz (D)
}

Accepted: 27 October 2020 / Published online: 25 February 2021

(C) The Author(s) 2020

\begin{abstract}
The present research investigates certification effects and rational herding in reward-based crowdfunding (RBCF) campaigns of cultural projects. Culture is a domain where expert opinion traditionally plays an important role. Consequently, to test the role of experts in collective behaviour and outcomes of crowdfunding campaigns, RBCF of cultural projects is a particularly relevant field. The authors analyse data obtained from France's leading RBCF platform, Ulule, and show that the contributing crowd is heterogeneous, both in terms of expertise and willingness to follow information cascades. Testing the impact of different backer categories on (1) campaign success, (2) composition of the crowd and (3) overall day-by-day funding dynamics, the study provides evidence of the existence of both a certification effect at the very beginning of a funding campaign, and dynamic herding later all along the campaign. Contributions from expert backers, whether specialized in the same creative industry as a given project or not, trigger additional contributions and improve the success probability of a funding campaign. Senior experts follow other senior experts, which supports normative social influence and, when specialized, they follow other specialized senior experts, which highlights taste-based homophily. We also show that junior experts, i.e. future serial backers, follow senior experts, particularly when
\end{abstract}

A. Petit $(\bowtie) \cdot$ P. Wirtz

University of Lyon, iaelyon School of Management, Magellan

Research Center, Lyon, France

e-mail: aurelien.petit@univ-lyon3.fr specialized, which supports informational social influence. Experts hence lead the crowd in their decision to contribute to cultural projects, and those who follow them are mostly senior experts themselves and apprentice experts, not one-time contributors, which suggests the existence of community logic and rational information cascades in RBCF.

Keywords Reward-based crowdfunding · Culture · Experts $\cdot$ Information cascades $\cdot$ Rational herding

JEL classifications $\mathrm{G} 20 \cdot \mathrm{G} 41 \cdot \mathrm{L} 26 \cdot \mathrm{M} 13$

Crowdfunding (CF) has been progressively established in the entrepreneurial finance landscape over the last decade as an alternative or complement to more traditional forms of funding for projects (Alegre and Moleskis 2019; Block et al. 2020; Colombo et al. 2015; Mollick 2014; Moritz and Block 2016; Vismara 2016; Wallmeroth et al. 2018). Crowdfunding, defined as "a collective effort by people who network and pool their money together, usually via the Internet, in order to invest in and support efforts initiated by other people or organizations" (Ordanini et al. 2011) is not a homogeneous reality. Four different types of crowdfunding models are traditionally distinguished: peer-to-peer lending, equity-based, donation-based, and rewardbased (Kshetri 2015).

Much of the literature, however, "has largely treated crowdfunding as a homogeneous phenomenon by keeping a wide research focus and discussing all 
crowdfunding models as a unity. Over time, the important differences between the four crowdfunding business models have urged scholars to dissect the phenomenon into discernible segments" (Alegre and Moleskis 2019). To understand the drivers of individual contributions to a campaign, Cholakova and Clarysse (2015), for instance, show that contributions to projects on equity and reward-based platforms follow different types of motivation (extrinsic vs. intrinsic). Hence, the behaviour of contributors differs depending on the type of platform. As a consequence, funding dynamics over a campaign and ultimate campaign success can differ significantly from one type of platform to the other. Specifically, there appears to be a divide between campaign dynamics concerning platforms proposing a financial return (peer-to-peer lending, equity-based crowdfunding) and those without such financial returns (donations and reward-based crowdfunding) (Alegre and Moleskis 2019). For the former, among the various drivers of funding dynamics over a campaign's duration, herding and informational cascades have been advanced and documented as a significant explanation (Berkovich 2011; Herzenstein et al. 2011; Vismara 2018; Zhang and Liu 2012), whereas donations and reward-based campaigns appear to follow different or more complex patterns over time (Alegre and Moleskis 2019; Burtch et al. 2013; Kuppuswamy and Bayus 2018; Lin et al. 2014).

Recent research points out the foremost importance of equity-based crowdfunding for the field of entrepreneurial finance (Signori and Vismara 2018; Vismara 2019; Mochkabadi and Volkmann 2020). Yet, rewardbased crowdfunding (RBCF) has gained popularity in this research community (see for example Block et al. 2018; Giudici et al. 2018; Chan et al. 2018; Chan et al. 2019; Nielsen and Binder 2020), notably because "a large number of $[\mathrm{RBCF}]$ projects $[\ldots]$ turn into ongoing ventures" (Mollick 2018). RBCF has been shown to be a potentially important brick in the very early stage of emerging new ventures' funding trajectories (Bessière et al. 2020; Mollick 2018; Wallmeroth et al. 2018). Specifically, beyond money, RBCF campaigns help test the market, provide proof of concept and sustain learning of the entrepreneurial team. As stated by Pollack et al. (2019), "data on [RBCF] backers' behaviors can also contribute to entrepreneurship researchers' understanding of the role of crowdfunding in early market testing of entrepreneurs' ideas". Hence, a finegrained understanding of RBCF funding dynamics is an important contribution to research in entrepreneurial finance at large.

Explaining crowd behaviour through the lens of herding and informational cascades applies theory which has been long established in other fields of finance (Bikhchandani et al. 1992; Devenow and Welch 1996), but for which empirical testing proved difficult historically because of a lack of data. Hence Devenow \& Welch (1996, p. 612) stated two decades ago that "the foremost challenge to the herding literature may be the current scarcity of rigorous empirical evidence. [...] Communication channel traffic needs to be directly measured. Naturally, this data is difficult to get". Since crowdfunding platforms operate online, they produce massive data, not only on projects but also on backers and their contributions. The different actors also communicate online by posting comments and through social networks. Potential backers see the level of contribution by other backers. Hence, from the viewpoint of finance theory, crowdfunding holds the potential of being a natural testing ground for theories of herding and informational cascades.

As stated earlier, up to date, such work has been conducted essentially in the fields of equity-based crowdfunding and peer-to-peer lending. Excepting Lin et al. (2014), Colombo et al. (2015) and Chan et al. (2020), few attempts have been made to explore the heterogeneity of contributors in triggering herding in reward-based crowdfunding. The latter research is based on Kickstarter data. According to a recent systematic literature review by Alegre and Moleskis (2019), more than half of the prior studies use data from Kickstarter (34 out of 63 studies). We analysed a large dataset concerning backer contributions from Ulule, the leading RBCF platform in France. This distinguishes our contribution from most previous studies on reward-based crowdfunding. The possibility to test hypotheses related to herding and informational cascades depends on the visibility of specific information on preceding backer behaviour to potential future contributors. This visibility depends to a great deal on platform design. To make a story of informational cascades plausible requires us to ascertain which information on prior backer behaviour is readily and easily available to potential contributors when they access a project page. We were able to access 
an original database with particularly interesting features in terms of the visibility of the contributions from different types of backers. Ulule has a distinctive advantage for studying dynamics of rational herding, due to its specific platform design. Notably, it features its serial backers in a prominent position by granting them labels, which brings it close to a natural setting enabling the investigation of the impact of experts. It also prominently features and constantly updates the profiles of the last nine contributors of a project. Hence, all the ingredients are there to see whether other backers perceive contributions from experts as quality signals.

Lin et al. (2014) suggest that inconsistent results from preceding research may be due not only to differences in campaign and platform types but also to the fact that contributors are not a homogeneous crowd either, even for a given platform. Funding dynamics may also depend on the composition and nature of the contributing crowd (Signori and Vismara 2018; Vismara 2019). In their research on reward-based crowdfunding campaigns of cultural projects, for example Mollick and Nanda (2015) report results that show that the crowd features a high degree of wisdom in that its appraisal of projects corresponds to traditional experts' (art critiques) opinions, seemingly contradicting the idea that the ignorant crowd blindly follows other uninformed backers, where the blind would be leading the blind. But this does not mean that all forms of herding are necessarily absent from this kind of campaign. Distinguishing various categories of backers that make up a heterogeneous crowd can be a way to better understand the complex funding dynamics, which lead to aggregate collective outcomes. If those aggregate outcomes appear to be "wise" at the end, this could be due to the fact that a significant proportion of the crowd for some reason follows certain readily identifiable experts among the backers (we use the term backers interchangeably to designate funders/contributors) of a project. Kim and Viswanathan (2018) find evidence of such "rational herding" on a platform that had been created to fund ventures in the field of mobile apps, where expert backers exert a strong influence on the following contributions. Lin et al. (2014) suggest that such rational herding can also be found in reward-based crowdfunding and find some evidence in support of this idea. They segment the crowd into different categories (namely active contributors, followers, altruists, the crowd) and show that the contributions from active contributors have a significant positive influence on future contributions from all backer categories. We aim to extend the understanding of the segmentation of the crowd by focusing on the distinction between three types of backers:

- Senior experts, who can be identified by multiple past contributions, in as far as funding experience induces learning and leads to superior expert knowledge (Yang and Hahn 2016). As developed below, we expect them to trigger and to follow information cascades.

- Junior experts, who are first or second-time backers but who will become senior experts in the future. These apprentice serial backers are not recognized experts yet and thereby we do not expect them to trigger information cascades. However, as apprentice serial backers, they have to learn how to become an expert. Hence, they might be prone to rational herding by following contributions from senior experts.

- Both senior and junior serial backers can be specialized in one category of cultural projects (e.g. games, music...). We call them specialized (senior or junior) experts.

- First-circle backers (only one-time backers, who are mostly comprised of family and friends). We expect them neither to trigger nor to follow information cascades.

More specifically, we strive to answer three specific questions related to contributions from expert backers:

1. Is a high proportion of senior experts among early backers (the 21 first contributions labelled "early birds" on Ulule) exert a positive quality signal which certifies a high probability of campaign success?

2. Does the number of contributions from experts have an impact on the overall composition of the heterogeneous contributing crowd?

3. Does the cumulative number of contributions from experts influence the number of contributions on the following day? If so, do experts influence contributions from specific backer categories (one-time contributors, junior experts, other senior experts)?

Our results show that serial backers, specialized or not, notably when specialized in a specific project category, consistently and significantly influence (1) 
campaign success, (2) composition of the future crowd of backers and (3) day-by-day funding dynamics. Our principal findings show that specialized senior experts influence not only other specialized senior experts but also specialized junior experts, which supports the rational herding hypothesis. These findings also support the idea of a certain form of homophily, "the tendency of individuals to associate with others based on shared characteristics" (Greenberg and Mollick 2017), for example where amateurs of a cultural field (e.g. games) tend to cluster and form networks based on shared passion and common taste.

We make three distinctive contributions to the literature: (1) we study herding dynamics in the context of reward-based crowdfunding, a field where herding has not been as intensively investigated as compared with $\mathrm{P}$ to $\mathrm{P}$ lending and equity-based crowdfunding. (2) We provide empirical observations from an original data-set sourced from Ulule, a reward-based platform whose specific design is particularly prone to study rational herding dynamics. In addition to its specific platform design, French-based Ulule is also interesting because previous research has shown that crowdfunding dynamics and outcomes may depend on institutional context (Vismara 2016), and up to date, research on RBCF has to a great extent been conducted using data from Kickstarter. (3) We contribute to recent efforts directed at understanding the heterogeneity of the crowd and its impact on funding dynamics (Alegre and Moleskis 2019; Lin et al. 2014; Vismara 2019; Wang et al. 2019). More importantly, if senior experts have already been identified as triggers and followers of cascades in other contexts, we also examine how juniors learn from senior experts of a specific cultural category by herding behind their contributions. Indeed, "observational learning" has been advanced as a mechanism whereby information asymmetry may be reduced among the members of social networks which emerge in a crowdfunding context (Colombo et al. 2015), hence favouring campaign success. In a major stream of research, social capital derived from social networks has been proposed as one possible explanation of campaign outcomes in terms of the amounts raised and the number of contributing investors (Colombo et al. 2015; Vismara 2016; Giudici et al. 2018). In most of this research, the unit of analysis is however typically a project's proponent (cf. Colombo et al. 2015). His social capital can be expected to be a positive signal for the backer community, leading to an increased number of contributions. Our own research is focussed on the backers (not the proponents of a project) and the dynamics of the cascades they trigger and potentially reinforce. Hence, we believe our contribution to be complementary to work on proponents' social networks as exemplified by Mollick (2014), Colombo et al. (2015), and Vismara (2016) in a quest for an increased understanding of the various dimensions of the complex social interactions occurring in an online digital setting.

The remainder of the article is structured as follows. Section 1 presents a brief literature review on RBCF of cultural projects as well as on information cascades and herding (in general and in crowdfunding). Based on this prior literature we propose a series of testable hypotheses. In section 2, we explain the empirical research setup. Section 3 presents and discusses the results from the various panel regressions. Section 4 concludes.

\section{The role of experts in RBCF campaign dynamics of cultural projects}

\subsection{Herding in different crowdfunding platform types}

Previous literature on crowdfunding has established that backer contributions are particularly exposed to herding and information cascades because of the sequential nature of funding dynamics (Agrawal et al. 2014). Accumulated capital from prior contributions appears to be a good predictor of contributions to follow (Agrawal et al. 2015; Zhang and Liu 2012; Burtch et al. 2013). But two opposite hypotheses on herding could emerge, depending to a large extent on the type of crowdfunding platforms:

- The substitution effect: in donation-based crowdfunding markets, the "marginal utility contributors gain from giving to a particular project is diminished" (Burtch et al. 2013, p. 501) through the contribution of other backers. This leads to "negative downward informational cascades and ultimately a stagnation of contributions" (Thies et al. 2014). Donations on an allor-nothing crowdfunding platform may generate free-riding issues, as the donations of other backers may be sufficient for a campaign to succeed (Solomon et al. 2015). Reciprocal giving, and not only pure utilitarian motives, favour success in reward-based crowdfunding, notably on 
Ulule (André et al. 2017), or even on Kickstarter, which forbids funding of charities (Thürridl and Kamleitner 2016; Dai and Zhang 2019). This effect could be verified in reward-based crowdfunding for the last days of a project, especially in the categories Charities, Environment and Education, where altruistic motives are supposedly strong. But we do not expect this substitution effect to occur in other categories.

- The complementarity effect: in equity- and lendingbased crowdfunding markets, signals of quality are implicitly given by previous investors (Herzenstein et al. 2011). For those campaign types generating financial returns, signals conveyed through previous massive contributions by the crowd have thus been shown to trigger upward cascades (Berkovich 2011; Herzenstein et al. 2011; Vismara 2016; Zhang and Liu 2012). The funding pattern appears to be more complex for reward-based platforms, but the quality of projects also matters in the latter (Thies et al. 2014; Frydrych et al. 2014), particularly when entrepreneurs pre-sell their products on these platforms. For those products, backers are mostly consumers who receive their products if the funding goal of the project is reached. Ulule signals pre-sales on a project's page. Such pre-sales are strongly present in some categories like Fashion \& Design, Journalism \& Edition, Games or Comic Books. Complementarity effects lead to upward informational cascades and ultimately help entrepreneurs to reach (and even outreach) their funding goal. This herding effect can be considered to be rational if backers integrate previous contributors' choices as rational quality signals (Zhang and Liu 2012). Rational conformity of contributions can also come from positive payoff externalities (Devenow and Welch 1996), notably on reward-based platforms applying an all-ornothing system, as Ulule: if a project does not reach its funding goal, the entrepreneur does not receive any funds and the backers neither contribute nor receive their counterparts. Contributing to failed campaigns could discourage backers (Lumeau et al. 2018). Then, conformity of contributions can come from positive payoff externalities: when a sufficient number of people back a project, these people know that they might obtain their counterparts.
1.2 Crowd composition in RBCF of cultural projects

In the present research, we assume that the crowd of backers is heterogeneous, and hence not all backers should be expected to have the same influence on funding dynamics during the following days, as well as on the ultimate campaign success. The existence of backer heterogeneity has been attested in other crowdfunding categories than RBCF. In equity crowdfunding, for instance, Signori and Vismara (2018) and Vismara (2019) distinguish between restricted investors and sophisticated professional investors, such as VCs, and show that they influence funding dynamics and venture success in a distinct way, because institutional logic pushes each group to pursue different objectives. Institutional logic has it that professional investors pursue primarily financial objectives, whereas restricted investors tend to follow sustainable objectives according to the standards of the specific community they belong to (Vismara 2019). In reward-based crowdfunding of cultural projects, it is reasonable to expect professional investors to be (almost) absent, since the relatively small contributions to this type of platform are not an investment in a venture's equity stake. Still, even if we assume restricted investors to be pervasive in cultural RBCF, differences inside this category may be of importance. In particular, serial backers may become special advocates for a project. Elena Mikhaylova, CEO of CrowdfundProductions and serial entrepreneur on crowdfunding platforms, highlights that "serial backers are the spinal cord of Kickstarter. They not only pledge more money, but also actively share your campaign in social networks, bringing more backers on board, and comment on your page offering their expertise."1 These serial backers could be perceived as impartial, as they do not belong to the first circle (family and friends) of project holders and share less geographical proximity with them (Petit 2018), which can secure higher funding (Kang et al. 2017). Serial backers may have different characteristics compared with new ones. As returning consumers, they have a better risk perception (Pavlou 2003; Kim and Gupta 2009) and are less influenced by network effects (Hahn and Lee 2013). Studying French RBCF platforms Kisskissbankbank and Ulule, Petit (2018) shows that

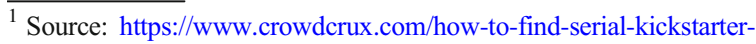
backers/
} 
serial backers are younger, more experienced as project holders and use different channels of contribution compared with new backers. They are also more prone to complete their public profile on Kisskissbankbank, which has been shown to be a factor favouring information cascades among investors in equity crowdfunding (Vismara 2016).

In which project categories on RBCF platforms may serial backers be expected to play a particularly important role? From an economic perspective, the creative industries feature strong specificities (Caves 2003) concerning the quality and value of projects. Arts and entertainment are distinct from other sectors due to the "fundamental uncertainty" in terms of the predictability of the audience's perception of quality (Caves 2003, p. 74). For that reason, experts and opinion leaders play a fundamental role in the creative cultural industries (Reinstein and Snyder 2005; Mollick and Nanda 2015). Reward-based crowdfunding of creative cultural projects may thus be a particularly relevant testing ground to see if crowd dynamics of backers are significantly influenced by those who can be identified as experts in the crowd. Mollick and Nanda (2015) and more recently Bernard and Gazel (2018) have shown that crowdfunding campaigns of creative cultural projects value projects close to expert judgement when campaign outcomes are compared with a panel of expert opinions. They refer to this phenomenon as the "wisdom of the crowd". If the crowd exhibits such wisdom in the evaluation of cultural projects, we may expect this collective wisdom to be the result of rational herding, where contributors observe the quality signals emanating from previous backers who are perceived as experts. Devenow and Welch (1996) note that "herding does require a coordination mechanism. This mechanism can be either a widely spread rule to coordinate based on some signal" (e.g. in the case of Ulule a selection by the platform of quality projects or a mention of the project in the newsletter, or a quality signal given by the project creator, such as his past experience, which we cannot test here), or based on a direct ability to observe other decisionmakers". Hence, we designed a research setting that allows testing the impact of such an ability to observe other decision-makers.

Quality signals emanating from other decisionmakers can come in various forms: the quality and expertise of the contributors per se, or the decision they make concerning the nature of their contribution. In the first case, if potential backers can readily identify the experts among the contributing crowd, a large number of expert backers can be supposed to be a positive quality signal. In the second case, the amount of money invested by experts can also have a signalling effect (Hornuf and Schwienbacher 2018; Wang et al. 2019). To operate as a signal to potential backers, however, the amounts of contribution must be observable. This depends on platform design, and Ulule does not feature such information. Hence, for the present research, as potential backers do not have access to the amount of previous contributions, it seems relevant to cast our hypotheses to test the impact of the past number of contributions by experts rather than the average amount contributed.

\subsection{Hypotheses on funding dynamics in RBCF of cultural projects}

\subsubsection{Certification made by expert early birds}

One possible approach is to test the impact of early contributions from experts (number of experts among the early birds) on campaign outcomes, such as ultimate campaign success or the overall composition of the contributing crowd. Colombo et al. (2015) note that "it is conventional wisdom that what happens at the beginning of a community has a crucial impact on its subsequent evolution." In particular, the number of early contributions may be interpreted by potential backers as a sign of quality that may trigger herding (Colombo et al. 2015). But the early backers of a project may be heterogeneous, and all types of early backers do not necessarily exert the same influence. Typically, on reward-based crowdfunding platforms, family and friends tend to be early project supporters (de Witt 2012), but in reality, even initial crowds in RBCF may be more complex than just family and friends, at least for certain projects. In the present study, we complete prior results concerning the size of the initial community by focusing on the composition of the crowd rather than on its size. As stated by Fisher et al. (2017), entrepreneurs can establish venture legitimacy by creating ties with prominent community members of crowdfunding platforms dominated by a community logic. As a matter of fact, community logic may be expected to be especially pervasive in RBCF of cultural projects. Since those projects do not offer a financial return, they should be expected to attract mainly what Signori and Vismara 
(2018) and Vismara (2019) call "restricted investors". The latter are shown to have a "communitarian predisposition" (Vismara 2019, p. 101), and their investment behaviour hence follows the particular values of their specific community. In communities supporting cultural projects, it is reasonable to suppose that readily identifiable experts are perceived by others as strong proponents of community values.

Recognized experts among early birds could thus generate associative mechanisms that improve the legitimacy of a project among a RBCF community. On Ulule, on the right side of a project page, just below the rewards section, a potential backer sees the 21 first backers of the project, which are called "early birds". A first potential way of testing the impact of quality signals from experts is thus to examine if early contributions made by expert early birds (serial backers) are associated with a higher probability of ultimate campaign success. As a matter of fact, such a way to proceed is not a test of a cascade, since the dependent variable (campaign success) is static: during the campaign, the funding goal is either reached or it is not, but day-by-day funding dynamics over the campaign duration are ignored. It is still an interesting way to approach quality signals and certification effects. To do this, we distinguished the 21 first backers from the following contributors to a project and identified senior experts, defined as serial backers in general, as well as specialist senior experts (specialized in the same category as the project), among the early birds.

Hypothesis 1: The number of contributions made by senior experts among the early birds has a positive influence on the probability of success of the project ( 1 if the goal is reached, 0 otherwise).

The number of senior backers among the early birds may also have an influence on the overall composition of the future contributing crowd, since not all backer categories are likely to follow signals emanating from experts to the same degree. Unlike other categories of the crowd, senior experts have greater experience and knowledge when making their decision (Yang and Hahn 2016). On the one hand, one can thus expect senior experts to make up their own mind, which reduces the likelihood of herding for reasons linked to information deficits. Consequently, informational cascades stricto sensu
(Bikhchandani et al. 1992) are quite unlikely to occur among serial backers who share expert knowledge.

But on the other hand, there may still be strong reasons for them to cluster around other senior experts. Indeed, if financial motivations are paramount in ECF, utility-driven motivations are still important in RBCF (Cholakova and Clarysse 2015). However, in addition to the desire to collect rewards, Gerber and Hui (2013) find that backers on Kickstarter also want to support causes, help others and, what interests us most here, being part of a community. Bretschneider and Leimeister (2017) also add that backers seek notably recognition from others in return for investment. With a non-hierarchical cluster analysis, Ryu and Kim (2016) classify RBCF backers into four categories: angelic backers, reward hunters, tasteful hermits and avid fans. They define in particular the latter as a passionate sponsor group of crowdfunding natives, similar to members of a brand community. These avid fans particularly distinguish themselves from the other groups by their motivation scores on the recognition and relationship scales. If we cannot test it precisely, these features fit likely with the community of serial backers on Ulule. According to psychologists (Hung and Plott 2001), conformity of behaviour in communities can have two potential origins: "informational social influence" where information is inferred from the behaviour of other members of the group, and "normative social influence" where the internal motivation is due to the need of conformity to the perceived norms of the group. The former seems to be less relevant than the latter for senior serial backers. This is also consistent with the community logic identified by Vismara (2019) as an explanation of the specific investment behaviour of so-called restricted investors who contribute to crowdfunding campaigns for other reasons than financial returns. As argued above, this investor type is pervasive in $\mathrm{RBCF}$ of cultural projects. Hence, normative social influence should be expected to lead to conformity of contributions among the overall group of serial backers on Ulule.

Hypothesis 2: The number of senior experts among the early birds has a positive influence on the number of future contributions from other senior experts.

In addition, previous research (e.g. Aral et al. 2009; Greenberg and Mollick 2017) has shown that 
homophily can be a driver of contributions to crowdfunding. Prominent research of homophily in crowdfunding was specifically designed to detect the impact of gender homophily (Greenberg and Mollick 2017), without being exclusive of other forms of homophily. There are multiple dimensions of homophily at work in social networks (McPherson et al. 2001). In a recent study, Dahlin et al. (2019) find that what they call "taste-based homophily, as defined by fundraisers with projects in the same category (dance, music, etc.), does have a strong influence on the likelihood of reciprocity" in Kickstarter campaigns. For the consumption of cultural goods at large, the cultivation of taste has been identified as a much more important phenomenon than in any other field of the economy (McCain 1995). Taste-based homophily may thus be supposed to be a particularly prevalent influencer of expert serial backers clustering together in RBCF campaigns of cultural projects. Hence, specialized early-bird senior experts can be expected to attract other specialized senior experts.

Hypothesis 2s: The number of specialized senior experts among the early birds has a positive influence on the number of future contributions from other specialized senior experts.

Furthermore, we argue that another group might be prone to herd behind the contributions from senior experts: junior experts. We define the latter as apprentice serial backers. At one point, they are not serial backers yet, but will become so as time passes on. As senior experts, juniors might be sensitive to "normative social influence" (Hung and Plott 2001), because they want to become part of the social group, or community (Vismara 2019), of senior experts by backing the same projects. Moreover, junior serial backers might want to mimic seniors because they infer them to have more information thanks to funding experience. This type of herding triggered by "informational social influence" (Hung and Plott 2001) is consistent with a logic of informational cascades. Consequently, it is reasonable to suppose that the presence of senior experts among the early birds attracts junior experts.

Hypothesis 3: The number of contributions made by senior experts among the early birds has a positive influence on the number of future contributions made by junior experts.
As for specialized senior experts, juniors who will become experts of a given cultural category might follow senior experts of this category, for the same reasons as junior experts might follow senior experts and because of taste-based homophily. Admittedly, homophily of taste may be less of an issue for junior experts than for senior experts, because as apprentice experts they are still cultivating their tastes and gathering experience. Conversely, the certification effect supported by the observation of easily identifiable senior experts may be especially prevalent in this case.

Hypothesis 3s: The number of contributions made by specialized senior experts among the early birds has a positive influence on the number of future contributions made by specialized junior experts.

This contrasts with the expected behaviour of one-time backers from the first circle, such as family and friends. The latter contribute because they know and like the project leader. Hence, the number of one-time backers as compared with the number of serial backers following the first 21 contributions from early birds is likely to be independent from the specific nature of early birds (presence of senior experts). Because of their emotional ties, it seems reasonable to suppose that most of the family and friends of a project's creator would back the project whatever previous contributions there are. This socalled "first circle" is composed of one-time contributors who are driven by personal ties (Polzin et al. 2018) to the project leader, not by expert opinion. Hence, it is reasonable to suppose that the number of senior experts among the early birds has no significant impact on future one-time backers' contributions.

Hypothesis 4: The number of senior experts among the early birds has no significant influence on the number of first-circle backers who do not intend to become serial backers in the future.

\subsubsection{Herding triggered by experts}

Beyond a static certification effect at the start of a project, our data also allow for the study of day-by-day funding dynamics. This may be a way to test if rational 
cascades occur all along a funding campaign. Looking beyond early birds, we thus investigated the influence of expert backers on day-by-day funding dynamics to understand if backers on day +1 pay particular attention to quality signals emanating from previous backers who can be identified as experts. Much of the underlying reasoning developed to support hypotheses concerning the certification effect can be transposed to a dynamic setting to test if arguments akin to community logic, homophily and quality signals emanating from serial backers also hold in day-by-day funding dynamics. We hypothesise that informational cascades in rewardbased crowdfunding of cultural projects are not only initially set off by expert backers present at the very origin (among the early birds) but also gain momentum as expert contributions occur and accumulate all over a campaign's lifespan.

Hypothesis 5: The number of prior contributions made by senior experts has a positive influence on the number of contributions on day +1 .

For the same reasons as those already developed to support the existence of a certification effect caused by early birds, we expect that not all backers are homogeneous in their response to signals emanating from experts on a day-by-day basis as the campaign moves on.

The hypothesised clustering (cf. hyp. 2) of senior experts around other senior experts due to normative social influence (Hung and Plott 2001) and community logic (Vismara 2019) can also be supposed to expand over the dynamic development of a campaign. The more senior experts contribute as the campaign unfolds, the more other senior experts they are likely to attract on the following days.

Hypothesis 6: The number of prior contributions from senior experts has a positive influence on the number of contributions from other senior experts on day +1 .

As for the static certification effect, taste-based homophily can occur dynamically all along a campaign between senior experts specialized in a given category of projects.

Hypothesis 6s: The number of prior contributions from specialized senior experts has a positive influence on the number of contributions on day + 1 made by the other senior experts specialized in the same category.

As argued before, junior experts might be prone to follow senior contributions because of normative and informational social influence. Besides the certification effect exerted by senior experts at the very beginning of a campaign, this might be observed dynamically, all along a campaign.

Hypothesis 7: The number of prior contributions made by senior experts has a positive influence on the number of contributions on day +1 made by junior experts.

The influence of senior expert backers is likely to be especially strong for follow-on contributions from junior experts when both are specialized in the same category of project. Indeed, when a backer only wants to contribute to one category of projects, the number of projects to assess is restricted. Therefore, informational social influence might be particularly important for specialized junior serial backers.

Hypothesis 7s: The number of prior contributions made by specialized senior experts has a positive influence on the number of contributions on day +1 made by junior experts specialized in the same category.

Conversely, one-time backers from the first circle primarily most likely contribute for reasons related to personal ties, whatever the expertise of the preceding contributors may be.

Hypothesis 8: The number of prior contributions made by senior experts has no influence on the number of contributions on day +1 made by firstcircle backers.

\section{Data collection and research methods}

\subsection{Key features of the platform}

The present study focuses on investment campaigns on Ulule, one of France's premier reward-based crowdfunding platforms for cultural 
projects. $^{2}$ This platform presents very interesting features to study the impact of crowd composition. Indeed, potential backers have easy access to signals concerning the expertise of prior contributors. A project page on the Ulule website (see Fig. 1 in the Appendix) actually features useful information on previous backers. Potential backers notably see the number of past contributions, the cumulated amount funded, the corresponding percentage of the funding goal, and when they click on the backers' tab, they see the past backers of this project in descending chronological order, in particular the last nine backers who are prominently featured. This is not the case for example on Kickstarter, the world-leading RBCF platform, which only presents (on the community tab of a project's page) aggregated information on the number of previous contributions to a project made by first-time and serial backers. On Ulule, when clicking on a particular backer, information immediately pops up, revealing all projects (and categories: games, comics, ...) he previously supported. For a potential backer of a project, it is hence quite easy to see how many projects belonging to a particular category were previously funded by the various contributors before him. It is important to notice that a potential backer has no information on the amount of previous backers' contributions, which is why we do not consider these amounts in this study. Further, Ulule automatically attributes so-called "badges" to "special" backers. The third project a user backs entitles him to a badge labelled "Serial Ululer". The same applies for some categories of specialized backers (e.g. Games, Literatureincluding Comic Books - but not for Theatre \& Performing Arts). Serial backers who repeatedly invest in and follow the same project category (e.g. games) with ongoing attention can thus be identified as specialized experts. Therefore, potential contributors who click on a project page can

\footnotetext{
${ }^{2}$ Ulule's headquarters are based in Paris, but the company is also growing in Montreal, Barcelona, Rome and Antwerp. This international growth is too recent to consider projects out of France in this study, but future research might investigate differences across countries. Ulule has raised about 31 million $€$ in 2018 for 8148 projects, compared to a total of 68 million $€$ raised on all French reward-based crowdfunding platforms (source: "Baromètre du crowdfunding en France 2018", KPMG - FPF). Hence Ulule approaches a 50\% market share of reward-based crowdfunding in France.
}

very easily identify all prior contributors and distinguish the experts among them. Ulule encourages project creators to look at contributions from experts: "Do not hesitate to follow influential Ululers in your field (or in general!) to make yourself known. You multiply your chances that they take a look at your project and come follow

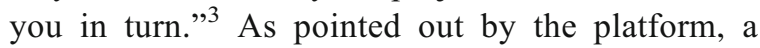
project can benefit from contributions from experts in general (of the platform) or from experts in the specific cultural field of the project (e.g. games or comic books). Theoretically, both can trigger upward rational informational cascades, albeit to different degrees, as there are generalist experts and specialized experts, identifiable as such by the crowd.

There are different ways of approaching the effect of quality signals emanating from experts. One should note that quality signals must be readily observable to be eligible as a driver of campaign outcomes. If they are observable depends very much on platform design. If we take the contribution from an expert as a quality signal, two ways of identifying a signal can be imagined: the number of contributing experts or the amount of money spent by contributing experts. Ulule does not provide information on the amounts contributed by individual backers. Hence, would-be contributors cannot observe the amount of contributions from experts, but only the number of contributing experts at each point of time.

\subsection{Sampling}

Ulule is presently the leader platform for reward-based crowdfunding in France. It is a generalist platform and was launched at the end of 2010. In this study, we initially considered projects launched after January 1, 2011, and closed before June 30, 2018. To distinguish junior experts from senior experts who already backed at least 3 projects at the time of a contribution, we restrict the sample to the period covering January 2014 to June 2018 in the following regressions. After cleaning the data, we obtain 17,606 projects in all categories except Charities, Education and Environment. The categories are defined as Ulule does: using the Ulule tags Art \& Photo, Comics, Crafts \& Food, Film \& Video,

\footnotetext{
$\overline{3}$ Source: https://community.ulule.com/topics/how-to-optimize-thebulp-badges-17004/
} 
Fashion \& Design, Games, Heritage, Journalism \& Edition, Music, Sports, Stage. Technology and the Ulule tagname Green are used to exclude projects of this category. Ulule categories Charities \& Citizen and Childhood \& Education are also excluded, as argued before, since the focus of our study is on cultural projects. Ulule categories Act for Impact and Women Entrepreneurship are recent and do not include a sufficient number of observations to be included in the sample.

Contributions made by the creator of a project or by members of the Ulule staff are excluded (following a recommendation from Crosetto and Regner 2018). Focusing on cascades, we are not interested in repeated contributions to the same project. Consequently, if the same backer contributes more than once to one particular project, we only consider the first contribution ( $90.8 \%$ of all contributions).

\subsection{Discussion of panel models to test herding}

As endogeneity issues are paramount when studying cascades with dynamic panel data, we choose the Generalized Method of Moments as our core model to test hypotheses 5 to 8 (Tables 6 and 13) on a day-by-day basis. In these linear dynamic panel regressions, we choose to restrict the sample to funding campaigns of 46 days (which provide the highest number of daily observations) for sake of clarity of interpretation on a balanced panel and for computation limitations. One drawback of this way to proceed is that it somewhat simplifies the platform setting. Our goal is to test the impact of easily identifiable signals on potential backers.

We provide two types of robustness tests. Both of them have the very important drawback not to consider endogeneity issues. However, they allow for testing herding on a contribution-by-contribution basis, which is more precise and closer to the setting of the platform than the day-by-day basis used in the GMM regressions. As computation limitations are lower than for GMM models and because unbalanced panels do not hurt the interpretation of the results, here we include all projects in all categories except Charities, Education and Environment, not only funding campaigns of 46 days. In these models, the independent variables of interest are dummy variables equal to one if either the previous contribution is made by a first-time/or a senior expert, specialized or not (in Tables 14, 16 and 18), or the share of first-time/ senior experts, specialized or not, among the nine previous contributions (in Tables 15, 17 and 19).
The first type of robustness test relies on duration analysis, with Cox proportional hazards models and Efron method to handle tied failures, where the dependent variable (the failure rate in these models) is inversely proportional to the time elapsed since the last contribution (Table 14), or to the average time since the last nine contributions (Table 15). We assume that this failure rate depends on the composition of the crowd of previous backers. We use this type of model as robustness tests of hypotheses 5 to 8 .

The second type of robustness tests relies on panel probit regressions, with random-effects. In this model, the dependent variable is a dummy variable equal to one if a first-circle/junior/or senior backer contributes. By construction, this model does not allow for testing hypothesis 5 . We use it as a robustness check of hypotheses 6, 7, 8 (Tables 16 and 18) as well as hypotheses $6 \mathrm{~s}$ and $7 \mathrm{~s}$ (Tables 17 and 19).

\subsection{Variables of interest}

There is no evident empirical definition of serial backers. Ulule grants badges "Serial Ululer" to users who backed at least 3 different projects. This is rather few to identify serial backers who could be recognized by other backers as influencers, but we choose to keep this study close to platform design, because we assume that cascades are driven by easily observable signals.

Consequently, for the purpose of the present study, "senior experts" are defined empirically as backers who, when contributing at one specific point of time during the January 2014 to June 2018 time span, had backed at least 3 different previous projects. Even if we cannot test this hypothesis, it seems likely that backers who contributed to at least 3 projects all created by family or friends are very few. The "senior experts" variable does not need ex-post information and is used as a dependent and as an independent variable.

Serial backers specialized in the category of a specific project (e.g. games, ...) may be more readily recognized as experts in this category. For each project, we define "specialized senior experts" as users who previously backed at least 3 different projects of the same category.

"First-time backers" indicates backers who are backing their first project at the time of the contribution. This variable does not need ex-post information and is used as an independent variable. First-time backers could turn 
out to be junior serial backers or first-circle backers for example.

"Junior experts" indicates backers who, at one point of time, were backing their first or second project, but who turned into serial backers later on (before June 2018). This definition of junior serial backers relies on ex-post information: the number of future projects backed by unexperienced backers at the time of their first contribution. But when a potential backer clicks on a project's previous backer, the former does not know if the latter will back other projects in the future. This is why we use the "junior experts" variable as a dependent variable only. We also define "specialized junior experts" as juniors at one point of time who will back at least 3 projects of the same category in the future.

"First-circle backers" are first-time backers, but who never back any other project until the end of the total time span covered by our study: they are one-time backers. The construction of this variable also requires ex-post information. It appears reasonable to believe that this variable is a good proxy of the family and friends of the project creators, or at least only includes these and no junior or senior serial backers, our other variables of interest.

\subsection{Descriptive statistics}

Hypotheses 1 to 4 are static: when senior experts are part of the first backers of a project, it may be a signal of quality, which has a presumably positive impact on its chance of success and future contributions from senior and junior serial backers. Table 1 presents descriptive statistics of the variables used to test the static certification effect (Tables 3, 4 and 5). Table 7, in the Appendix, provides statistics on the subsample composed of the categories Games, Comics, Video, Music and Journalism, i.e. those with the highest number of serial backers in June 2018. It has to be noted that 6055 projects with 21 contributions or less are not included in these regressions, by construction, which excludes a large part of failed projects and increases the average percentage of projects' success (around 92\%, which is more than 20\% higher than this ratio for all projects). Most early birds are first-time backers (16.37 out of 21 on average), while specialized senior experts represent around 4\% of early birds (6\% when considering only the 5 categories with the highest numbers of specialized serial backers). These ratios are similar for contributions made after the first 21 , which means that, on average,
Table 1 Descriptive statistics of the static samples of projects used to test the certification effect

\begin{tabular}{|c|c|c|c|c|}
\hline Variable & Mean & Std. err. & Min & Max \\
\hline \multicolumn{5}{|c|}{$\begin{array}{l}\text { Projects in all categories except Charities, Education and } \\
\text { Environment (11551 projects) }\end{array}$} \\
\hline Goal raised & 0.92 & 0.27 & 0 & 1 \\
\hline \multicolumn{5}{|c|}{ No. of contributions after the first 21 made by: } \\
\hline All backers & 61.75 & 158.48 & 1 & 7792 \\
\hline Senior experts & 7.66 & 25.39 & 0 & 701 \\
\hline Specialized senior experts & 2.79 & 11.97 & 0 & 349 \\
\hline Junior experts & 4.70 & 19.83 & 0 & 851 \\
\hline Specialized junior experts & 2.12 & 9.43 & 0 & 367 \\
\hline First-circle backers & 39.43 & 95.04 & 0 & 5024 \\
\hline \multicolumn{5}{|c|}{ No. of contributions in the first 21 made by: } \\
\hline Senior experts & 2.09 & 2.72 & 0 & 21 \\
\hline Specialized senior experts & 0.82 & 1.93 & 0 & 21 \\
\hline First-time backers & 16.37 & 3.88 & 0 & 21 \\
\hline
\end{tabular}

Data: Ulule, January 2014-June 2018. Only projects with more than 21 contributions are included

specialized serial backers do not contribute earlier (considering the 21 first contributions) than all types of backers. However, senior experts in general tend to be slightly overrepresented among early birds (10\% compared with $8 \%$, or $14 \%$ compared with $12 \%$ when considering only the 5 categories with the highest numbers of specialized serial backers).

Early contributions made by experts might be interpreted as signs of quality that trigger additional contributions and improve a project's success probability. But later expert contributions, all along the funding campaign, may also attract other backers. To test hypotheses 5 to 8 , we look at the dynamic role played by experts to capture possible cascades. To disentangle dynamic herding from static certification, we now exclude projects' early contributions. To study herding behaviour, we are interested in the effect of the cumulated number of contributions to one project (made by different types of backers) on the number of contributions to this project the day after. To do so, we build a dataset with one line by project and day. To work on a balanced panel, and for computation limitations, we restrict the sample to the campaigns of 46 days as they present the highest number of observations (2000 projects for 84,000 observations after excluding the first decile of 4 days, which represents $12.5 \%$ of the sample). We also restricted the sample to projects counting at least one contribution after the first decile of the 
Table 2 Descriptive statistics of the dynamic panels used to test the herding effect

\begin{tabular}{|c|c|c|c|c|c|}
\hline Variable & Obs & Mean & Std. dev. & Min & Max \\
\hline \multicolumn{6}{|c|}{ Projects with funding duration of 46 days in all categories except Charities, Education and Environment (1187 projects) used in Table 6} \\
\hline \multicolumn{6}{|l|}{ Daily number of contributions by project made by: } \\
\hline All backers & 49854 & 1.69 & 4.41 & 0 & 284 \\
\hline Senior experts & 49854 & 0.20 & 0.96 & 0 & 58 \\
\hline Specialized senior experts & 49854 & 0.08 & 0.43 & 0 & 22 \\
\hline Junior experts & 49854 & 0.12 & 0.63 & 0 & 56 \\
\hline Specialized junior experts & 49854 & 0.03 & 0.23 & 0 & 16 \\
\hline First-circle backers & 49854 & 1.11 & 2.80 & 0 & 147 \\
\hline \multicolumn{6}{|c|}{ Daily cumulated number of contributions by project made on T-1 by: } \\
\hline First-time backers & 49854 & 39.64 & 81.54 & 0 & 2294 \\
\hline Senior experts & 49854 & 6.16 & 20.15 & 0 & 598 \\
\hline Specialized senior experts & 49854 & 2.43 & 8.81 & 0 & 187 \\
\hline \multicolumn{6}{|l|}{ Daily control variables on $\mathrm{T}-1$} \\
\hline No. of projects on Ulule & 49854 & 1037.81 & 388.32 & 135 & 5080 \\
\hline No. of projects in the category & 49854 & 5.46 & 4.57 & 0 & 30 \\
\hline Non-funded share (floored) of the funding goal & 49854 & 0.46 & 0.33 & 0 & 1 \\
\hline
\end{tabular}

Data: Ulule, January 2014-June 2018. Sample restricted to the 9 last deciles of a funding campaign duration and projects counting at least one contribution after the first decile of the campaign

campaign, as campaigns without early contribution are not suited to study herding and for econometric reasons (to lower the number of zeros), which leaves 1187 projects and 49,854 observations. Table 2 presents descriptive statistics of the overall panel of projects $\times$ days of funding and of the restricted panel used in the regressions of Table 6. Table 8 in the Appendix presents descriptive statistics on the subsample of five categories used in the regressions of Table 13. Table 9 in the Appendix presents descriptive statistics on the contribution-by-contribution panel used in the regressions of Tables 14, 15, 16, 17, 18 and 19.

On average, during one day of the last 9 deciles of a funding campaign duration, 1.69 backer contributed to a project, including 0.20 senior serial backer, which represents around $12 \%$ of the total, and 0.12 junior serial backer (around $7 \%$ of the total). The daily numbers of cumulated contributions are used as independent variables in linear dynamic panel regressions. The mean of cumulated contributions made by first-time backers is 39.64 and the mean of contributions made by serial backers is 6.16 including 2.43 for specialized senior serial backer. The dispersions of these variables are high (e.g. from 0 to 284 backers when considering only funding campaigns of 46 days). Figure 2, in the Appendix, shows a growing trend and a seasonality of contributions, with notably fewer contributions in $\mathrm{Au}-$ gust. This seasonality of contributions seems similar for those made by serial backers, specialized serial backers (right-hand scale), first-time backers or all types of backers (left-hand scale). We include inter-project dynamics (Belleflamme et al. 2019), reflecting the fact that the number of other ongoing projects on the platform (or more specifically in the category) may affect the expected number of contributions to a project. As this number is highly correlated with seasonal variables, we do not include the latter in the regressions testing the hypotheses on herding.

As Zhang and Liu (2012) or Kim and Viswanathan (2018), we control the herding momentum. To do so, we include in the panel regressions the non-funded share of the funding goal (funding goal minus the cumulative amount of funding, divided by the funding goal), floored at zero, on day $-1{ }^{4}$ To control for the Ushaped form of contributions typically observed in earlier studies (Kuppuswamy and Bayus 2017), we use dummy variables for each decile of a campaign (for instance, a campaign of 46 days is composed of 10

\footnotetext{
${ }^{4}$ In the robustness tests presented in Tables 14, 15, 16, 17, 18 and 19, that do not rely on panel with daily data but finer-grained data, we rather use an alternative version of this variable computed on contribution-1.
} 
Table 3 Certification effect caused by the composition of "early birds", i.e. the 21 first backers, on the success probability and on the number of future backers of projects, in all categories except Charities, Education and Environment

Goal raised ( 0 if the campaign failed, 1 if succeeded)

(1)
(3)
Number of all backers after the first 21
$0.023 * * *$

(0.008)

Specialized serial backers

Serial backers

$$
\text { (0.005) }
$$

\section{Specialized serial backers}

Obs.

$P(F)$

$R^{2}$ (or pseudo)

$$
11551
$$

0

0.123
(5)

$$
-3.928 * * *
$$

(0.560)

(4)

$\begin{array}{lll} & \begin{array}{l}5.094 * * * \\ (0.792)\end{array} & \\ & & 4.098 * * * \\ & & (0.970) \\ & & 11551 \\ 11551 & 11551 & 0 \\ 0 & 0 & 0.139 \\ 0.145 & 0.144 & \end{array}$

This table presents results of probit models in columns (1) to (3), where the dependent variable is equal to 1 when the funding goal is raised, and results of OLS regressions in columns (4) to (6), where the number of future contributions made by all types of backers is the dependent variable. Each regression includes a constant term, category fixed effects, the logarithm of the project's goal, the month of project's start, the duration of the campaign, the number of ongoing campaigns on the platform at the start of the project and the number of ongoing campaigns in the same category at the start of the project as independent variables. Data: Ulule, January 2014 to June 2018. Only projects with more than 21 contributions are included. *,** and *** indicate significance levels at respectively $10 \%, 5 \%$ and $1 \% . R^{2}$ is a pseudo- $R^{2}$ for probit regressions

deciles of 4 or 5 days each; by construction, the first decile counts 4 days and the last counts 5 days). To distinguish herding from certification, we did neither include the first decile of each funding campaign duration in the GMM regressions of Tables 6 and 13 nor the duration analyses and panel probit regressions presented in Tables 14, 15, 16, 17, 18 and 19.

\section{Results}

\subsection{Certification effect}

To test hypothesis 1 , concerning the certification effect of expert early birds on funding campaign success, we ran probit regressions examining the impact of the number of different types of backers (first-time backers, senior experts, specialized senior experts) among the early birds on campaign success, i.e. the attainment of the ultimate funding goal (Table 3 ).

Table 3 reveals that, among the 21 first backers of a project, the number of serial backers in general and also the number of specialized serial backers is positively (and significantly at least at 1\%) correlated with success probability (columns 2 and 3), while the coefficient is significantly negative for first-time backers (column 1). These results hold when considering only the five project categories with the highest numbers of specialized serial backers (Table 10 in the Appendix). The magnitude of this effect is stronger for specialized serial backers, which suggests that these specialized experts are particularly well identified by the crowd as informed investors. Hence, the certification effect (hypothesis 1) appears to be corroborated when considering the effect of the share of experts among early birds, on the probability to attain a funding goal. ${ }^{5}$

We also ran OLS regressions, including the same control variables as in columns 1 to 3 of Table 3 , to test the impact of the composition of early birds on the number of future backers of this project (columns 4 to 6 in Tables 3 and 10). On average, one added senior expert among the early birds is associated with 5 additional backers (even slightly more when considering only the five categories with the highest number of serial backers). One added specialized senior expert among early birds leads to 4 additional backers, which somewhat shades the previous result on the strongest impact of specialists on success probability.

\footnotetext{
$\overline{5}$ As expert "early birds" might select high-quality projects (which are likely to succeed), endogeneity could be an issue. Unfortunately, with the available data, we did not find proper instruments to solve this issue.
} 
Table 4 Certification effect caused by the composition of "early birds", i.e. the 21 first backers, on the composition of future backers, in all categories except Charities, Education and Environment: main types of backers

Shares of the contributions after the first 21 made by:

\begin{tabular}{|c|c|c|c|c|c|c|}
\hline & \multicolumn{2}{|c|}{ Senior experts } & \multicolumn{2}{|c|}{ Junior experts } & \multicolumn{2}{|c|}{ First-circle backers } \\
\hline & (1) & (2) & (3) & (4) & $(5)$ & $(6)$ \\
\hline \multicolumn{7}{|c|}{ No. of backers among the first 21} \\
\hline $\begin{array}{r}\text { First-time } \\
\text { backers }\end{array}$ & $\begin{array}{c}-0.017 * * * \\
(0.000)\end{array}$ & & $\begin{array}{c}-0.004 * * * \\
(0.000)\end{array}$ & & $\begin{array}{l}0.030 * * * \\
(0.000)\end{array}$ & \\
\hline $\begin{array}{l}\text { Serial } \\
\text { backers }\end{array}$ & & $\begin{array}{l}0.028 * * * \\
(0.001)\end{array}$ & & $\begin{array}{l}0.004 * * * \\
(0.000)\end{array}$ & & $\begin{array}{c}-0.039 * * * \\
(0.001)\end{array}$ \\
\hline Obs. & 11551 & 11551 & 11551 & 11551 & 11551 & 11551 \\
\hline$F$ statistic & 139.2 & 200.1 & 38.07 & 33.98 & 302.8 & 249.2 \\
\hline$R^{2}$ & 0.397 & 0.441 & 0.102 & 0.0902 & 0.400 & 0.354 \\
\hline
\end{tabular}

No. of backers among the first 21

This table presents results of OLS regressions where the share of future contributions made by different types of backers is the dependent variable: senior experts in columns (1) and (2), junior experts in columns (3) and (4) and first-circle backers in columns (5) and (6). Each regression includes a constant term, category fixed effects, the logarithm of the project's goal, the month of project's start, the duration of the campaign, the number of ongoing campaigns on the platform at the start of the project and the number of ongoing campaigns in the same category at the start of the project. Data: Ulule, January 2014 to June 2018 . Only projects with more than 21 contributions are included. *, ** and $* * *$ indicate significance levels at respectively $10 \%, 5 \%$ and $1 \%$

Further, we look at the impact of the composition of early birds on the share of future contributions from different kinds of backers. First, Table 4 shows that senior experts are particularly prone to back a project with a high proportion of senior experts (column 2) among its early birds. This result also holds for specialized senior experts (Table 5), in a similar proportion.
The regressions on the subsample of the five categories with the highest number of specialized serial backers confirm these results (Tables 11 and 12 in the Appendix). Conversely, the number of first-time backers among the early birds has a negative effect on the share of senior experts, specialized or not. Hence hypotheses 2 and 2 s are corroborated, which supports

Table 5 Certification effect caused by the composition of "early birds", i.e. the 21 first backers, on the composition of future backers, in all categories except Charities, Education and Environment: specialized senior and junior experts

Shares of the contributions after the first 21 made by:

Specialized senior experts

(1)

$-0.009 * * *$

(0.000)

No. of backers among the first 21

First-time backers

Specialized serial backers

(2)

(3) (4)
(3) (4)

Specialized junior experts

\begin{tabular}{|c|c|c|c|c|}
\hline specialızed serıal backers & & $(0.001)$ & & $(0.001)$ \\
\hline Obs. & 11551 & 11551 & 11551 & 11551 \\
\hline$F$ statistic & 67.52 & 118.0 & 31.04 & 28.83 \\
\hline$R^{2}$ & 0.342 & 0.487 & 0.102 & 0.0843 \\
\hline
\end{tabular}

This table presents results of OLS regressions where the share of future contributions made by different types of backers is the dependent variable: specialized senior experts in columns (1) and (2) and specialized junior experts in columns (3) and (4). Each regression includes a constant term, category fixed effects, the logarithm of the project's goal, the month of project's start, the duration of the campaign, the number of ongoing campaigns on the platform at the start of the project and the number of ongoing campaigns in the same category at the start of the project. Data: Ulule, January 2014 to June 2018. Only projects with more than 21 contributions are included. *, ** and *** indicate significance levels at respectively $10 \%, 5 \%$ and $1 \%$ 
Table 6 Herding effect of daily contributions on all backers in all categories except Charities, Education and Environment

No. of daily contributions to a project made by:

\begin{tabular}{llllll}
\hline All backers & $\begin{array}{l}\text { Senior } \\
\text { experts }\end{array}$ & $\begin{array}{l}\text { Specialized senior } \\
\text { experts }\end{array}$ & $\begin{array}{l}\text { Junior } \\
\text { experts }\end{array}$ & $\begin{array}{l}\text { Specialized junior } \\
\text { experts }\end{array}$ & $\begin{array}{l}\text { First-circle } \\
\text { backers } \\
(6)\end{array}$ \\
\hline
\end{tabular}

\begin{tabular}{llll} 
Cumulative number of contributions on day -1 made by: \\
\multicolumn{1}{c}{ First-time backers } & $0.00668^{* *}$ & $-0.00141^{* *}$ & -0.000322 \\
& $(0.00325)$ & $(0.000676)$ & $(0.000187)$ \\
Serial backers & -0.00562 & $0.0124 * * *$ & \\
& $(0.0130)$ & $(0.00263)$ & \\
Specialized serial backers & & & $0.0120^{* * *}$ \\
& & & $(0.00156)$ \\
Lag 1 of the dependent & $0.799^{* * *}$ & $0.603 * * *$ & $0.579^{* * *}$ \\
$\quad$ variable & $(0.136)$ & $(0.128)$ & $(0.0681)$ \\
Observations & 48667 & 48667 & 48667 \\
No. of groups (projects) & 1187 & 1187 & 1187 \\
No. of instruments & 1160 & 1170 & 1170 \\
P(Hansen) & 0.203 & 0.248 & 0.250 \\
P(z(AR1)) & 0.00451 & $3.79 \mathrm{e}-05$ & $1.74 \mathrm{e}-10$ \\
P(z(AR2)) & 0.0610 & 0.0116 & $2.12 \mathrm{e}-06$ \\
P(z(AR3)) & 0.557 & 0.884 & 0.778 \\
$P(F)$ & 0 & 0 & 0
\end{tabular}

$\begin{array}{lll}-8.05 \mathrm{e}-05 & -4.59 \mathrm{e}-05 & 0.00591 * * \\ (0.000311) & (0.000110) & (0.00215) \\ 0.00131 & & -0.0167 * \\ (0.00113) & & (0.00887) \\ & 0.00356^{* * *} & \\ & (0.00114) & 0.876^{* * *} \\ 0.939 * * * & 0.724 * * * & (0.135) \\ (0.203) & (0.153) & 48667 \\ 48667 & 48667 & 1187 \\ 1187 & 1187 & 1160 \\ 1160 & 1160 & 0.205 \\ 0.187 & 0.188 & 4.92 \mathrm{e}-05 \\ 2.09 \mathrm{e}-06 & 4.99 \mathrm{e}-08 & 0.0170 \\ 0.000714 & 0.000344 & 0.881 \\ 0.617 & 0.529 & 0 \\ 0 & 0 & \end{array}$

All linear dynamic panel regressions (with lagged levels used as instruments starting at 3) include the share of the further amount to be funded (between 0 , when the funding goal is raised, and 1) on day -1 , dummy variables for each decile of a campaign and for the last day of campaign, as well as the number of ongoing projects on the platform or more specifically on the category and a constant term. Variables of interest are considered as endogenous. $\mathrm{P}(\mathrm{z})$ indicates the $p$ value of the Arrelano-Bond test for AR(1), AR(2) and AR(3) in first differences. Data: Ulule, January 2014 to June 2018. Sample restricted to the 9 last deciles of a funding campaign duration, projects counting at least one contribution after the first decile of the campaign, and to funding campaigns of 46 days (12.5\% of the sample). *, ** and *** indicate significance levels at respectively $10 \%, 5 \%$ and $1 \%$

previous results on normative social influence and tastebased homophily in the RBCF framework.

In addition, we observe in Table 4 that junior experts are also particularly prone to back a project with a high proportion of senior experts (column 4) among its early birds. This result holds for specialized junior experts (Table 5), who follow specialized senior experts, and when considering only the five categories with the highest number of specialized serial backers (Tables 11 and 12 in the Appendix). Conversely, the number of first-time backers among the early birds has a negative effect on the share of junior experts, specialized or not (column 3 of Tables 4, 5, 11 and 12). This corroborates hypotheses 3 and $3 \mathrm{~s}$ and supports the role of "informational social influence", even if the latter is difficult to disentangle from "normative social influence" in this context.
By contrast, the share of first-circle backers diminishes with the number of senior experts among the early birds, whereas it increases with the number of first-time backers among the early birds (columns 6 and 5 respectively of Tables 4 and 11). Hence, hypothesis 4 seems also to be verified, which reinforces the preceding results.

\subsection{Herding effect}

Since beyond a static certification effect, we set out to test rational cascades and herding, as a next step we examined the impact of experts on overall funding dynamics on a day-by-day basis (hypothesis 5). This was done in a restricted sample made up of the 9 last deciles of project duration, to avoid overlapping with the impact of early contributions measured by the certification 
effect. Since on Ulule a potential backer has information on all prior contributions to a project, not only those made during the previous day, we chose to test the effect of the cumulative number of prior contributions rather than the effect of the number of contributions made the day before only. To that end, we ran linear dynamic panel regressions $^{6}$ (difference and system GMM) and present their results in Tables 6 (on all categories of the sample) and 13 (in the Appendix, with robustness tests on the five categories with the highest number of specialized serial backers). Here, the dependent variable is the number of contributions made by all backers (columns 1), or by different types of backers (columns 2 to 6 to test hypotheses 6 to 8). The independent variables of interest, considered as endogenous, are the cumulative number of contributions made by different types of previous backers identifiable by a potential backer (first-timers as well as serial backers or specialized serial backers).

First-time backers (family and friends as well as potential junior experts) appear to have a significantly positive impact (at least at a significance level of $5 \%$ in Table 6 and $10 \%$ in Table 13) on contributions on day +1 , which is in line with previous literature (Agrawal et al. 2015). The marginal effect of such a contribution, however, is very small, between 0.006 and 0.007 , which means, ceteris paribus, that more than 160 past cumulated contributions from first-time backers are correlated on average with 1 additional contribution. Conversely, contributions made by senior experts do seem to influence dynamically the number of contributions on day +1 . Hence, hypothesis 5 is not verified when considering GMM in the panel with daily variables. However, finer-grained contribution-bycontribution analyses, based on duration models, do not confirm these results. Indeed, columns 1 and 2 of Tables 14 and 15 show that previous senior expert contributions tend to decrease the time interval (i.e. increase the frequency) between a contribution (made by any type of backer) and the previous contribution (Table 14) or the average contribution time of the last 9 contributions (Table 15). Conversely, when a first-time backer contributes to a project, the time interval to the next contribution increases. Hence, it seems that we cannot settle this issue: the models that are the closest to the platform setting tend to verify hypothesis 5 , while the

\footnotetext{
${ }^{6}$ We use one lag for the dependent variable and instruments starting at 3 lagged levels, which is a more appropriate model specification given the significance of Arrelano-Bond tests for AR(2), a two-step robust estimator and forward orthogonal deviations transformer.
}

model that considers endogeneity, but on a day-byday basis, does not.

When studying who herds in RBCF, we essentially try to identify potential followers of senior experts (specialized or not). First, columns 2 of Tables 6 and 13 tend to verify hypothesis 6 : senior experts follow dynamically the contributions made by other senior experts. More precisely, the number of contributions made by senior experts are associated with more contributions made by other senior experts the following day. These results are significant at least at a $1 \%$ significance level and hold on the subsample of the five categories with the highest number of serial backers and with alternative specifications (duration models in Tables 14 and 15, as well as random-effects probit models in Tables 16 and 17). This might show that normative social influence (Hung and Plott 2001) among the group of serial backers of the $\mathrm{RBCF}$ platform triggers dynamic herding among these recognized experts.

Second, we also observe herding among specialized senior experts. Columns 3 of Tables 6 and 13 show that the number of contributions made by specialized senior experts is associated with more contributions made by other specialized senior experts the following day. This result holds whatever the previously mentioned subsample and alternative specifications. This confirms hypothesis $6 \mathrm{~s}$. Besides the normative social influence explanation, this herding among serial backer experts of a specific cultural category suggests that taste-based homophily (Dahlin et al. 2019) is a source of herding in RBCF.

Third, results concerning hypothesis 7 are mitigated. Columns 4 of Tables 6 and 13 show that junior experts do not follow senior experts on a day-by-day basis. However, the results of random-effects probit regressions presented in Tables 16 and 18 (columns 4) suggest that if the previous backer is a senior expert, or if the proportion of senior experts is high among the last 9 backers, the probability that a contribution is made by a junior expert increases significantly. Duration analyses confirm these tendencies in Tables 14 and 15 (columns 6). Previous senior expert contributions tend to decrease the time interval (i.e. increase the frequency) between a contribution made by a junior expert and the previous contribution (Table 14) or the average contribution time of the last 9 contributions (Table 15). Hence, the models that are the closest to the platform setting tend to verify hypothesis 7 , while the model that considers endogeneity does not. 
Fourth, specialized junior experts tend to herd behind specialized senior experts. Hypothesis $7 \mathrm{~s}$ is verified on a day-by-bay basis (columns 5 of Tables 6 and 13) and on a contribution-by-contribution basis (columns 4 of Tables 17 and 19 for random-effects probit regressions and columns 12 of Tables 14 and 15). This herding phenomenon might have three sources: taste-based homophily, normative social influence as well as informational social influence. Nevertheless, as argued before, the latter seems to be the most likely. Indeed, specialized junior experts follow readily identifiable specialized experts. It is dynamic in the sense that it is valid on a day-by-day and on a contribution-by-contribution basis during the 9 last deciles of a campaign. This effect is slightly stronger than the herding of specialized senior experts when looking at Table 18, which is probably the most intuitive for interpretation: a contribution made by a specialized senior expert increases the probability of the next contribution of around $13 \%$ for specialized junior experts, compared with $8 \%$ for specialized senior experts. This hints at the existence of informational cascades in RBCF of cultural projects. Specialized junior serial backers, i.e. apprentice experts of a cultural category, tend to cluster around the contributions of easily identifiable senior experts of this category.

By contrast, as expected, first-circle backers do not follow senior experts (hypothesis 8). The effect is negative for all categories of the sample (at least at a $10 \%$ significance level, column 6 of Table 6) and not significant for the five categories with the highest number of specialized serial backers (column 6 of Table 13). When considering the contribution-by-contribution panel with randomeffects probit models (columns 6 of Tables 16 and 18), results also indicate that when a senior expert made the previous contribution (or that senior experts are numerous among the 9 previous backers), the probability that the next backer comes from the first-circle decreases. On the opposite, first-circle backers seem to herd behind first-time backers. This herding effect might be linked with social network connections between members of the first-circle of a project creator, which we cannot test with our data. However, as argued before, first-time backers include one-time backers (the proxy variable for first-circle backers) but not only. This question could be an interesting avenue for future research.

\section{Conclusion}

This study focused on rational cascades and herding following expert contributions to reward-based crowdfunding campaigns of cultural projects. To the best of our knowledge, it is the first study of its kind specifically designed for RBCF in the cultural industry, where previous studies of cascades and herding in crowdfunding specialized on equity-based crowdfunding (Vismara 2016), or on the funding of high-tech products (mobile apps) (Kim and Viswanathan 2018). Results are in line with certain findings of previous research showing that informational cascades do play a significant role in campaign funding dynamics of the cultural industry as well. They are also in line with previous research on various backer categories in crowdfunding where so-called "restricted investors" (Signori and Vismara 2018; Vismara 2019), who are pervasive in RCBF of cultural projects, feature funding behaviour strongly guided by the perceived norms and values of the emerging social network community. But we break down backer categories even further, to gain a more finegrained understanding. As a matter of fact, our findings are derived from an original empirical set-up revealing the importance of specific subcategories of the restricted-investor crowd typical for cultural $\mathrm{RBCF}$ as defined by their respective funding experience.

More specifically, we demonstrate the importance of experts (serial backers of the platform) in the following ways: (1) we first examined a static certification effect achieved by early expert contributions, (2) we decomposed the crowd of followers and focus on other experts and apprentice serial backers and (3) then looked at experts' impact on day-by-day funding dynamics over the whole campaign (excluding early contributions) to capture possible cascades.

1. Concerning the first specific contribution to the literature, our results show that early support by experts for crowdfunded cultural projects exerts a positive certification effect, significantly increasing the chances for campaign success and the number of future backers of a project. The more expert serial backers there are among the first backers of a project (early birds), the higher are the chances to reach the funding goal, even when taking into account the 
fact that these expert serial backers select highquality projects (controlling for endogeneity). This effect is even stronger for specialized serial backers, who can be considered as senior experts of a given project category (e.g. games, ...).

2. This certification effect is valid when considering jointly all types of backers. But within the crowd, two types of backers are particularly prone to back projects certified by early contributions made by senior experts: (i) other senior experts, likely to a certain extent because of normative social influence, and (ii) junior experts, defined as apprentice serial backers (those who are not serial backers yet, but will become so), probably more particularly because of informational social influence. In addition, specialized senior experts exert a certification effect on both senior and junior specialized experts, which reveals notably the importance of taste-based homophily in RBCF.

3. Our third contribution is to reveal the existence of information cascades and rational herding in cultural projects. Contributions from senior experts not only have a static impact on ultimate campaign success early on, but they also generate dynamic herding patterns over a campaign's total time span. If their effect on the whole crowd of backers without distinction is poorly robust, past cumulated contributions made by these serial backers are shown, each day, to trigger additional contributions from other senior experts. This effect is strongest for specialized serial backers, who generate dynamically additional contributions from both senior and junior specialized experts. By contrast, contributions from first-time backers have a rather negative influence on senior experts and no influence on junior experts. In addition, one-time backers, who are likely composed mostly by family and friends, do not herd behind serial backers, specialized or not. These results hint at the existence of dynamic rational herding: not only at its beginning but all along a funding campaign.

Beyond certification, cascades and herding, we also make a tentative contribution to a better understanding of the internal dynamics of the community logic observed for restricted investors in earlier crowdfunding research (Vismara 2019). Specifically, the interaction between senior and junior experts may be key for understanding the dynamic formation and enlargement of the digital social network community of supporters of specific project categories in RBCF. Distinguishing the specific category of junior experts, apprentices who will become senior experts in the future, and are observed to herd behind senior experts, reveals an interesting feature of the socialization process taking place in the digital community of serial backers. This would be an interesting avenue for additional future research.

One limitation of the present research is due to a lack of the available data, where we were only able to analyse the direct impact of prior contributions as a signal in an informational cascade, ignoring other possibly important information channels. More particularly, we did not have access to external data from the social media, which may be expected to play a role in information cascades. Information is potentially transmitted through posts typically made on specialized pages on Facebook (like "Actus Jeux Kickstarter, Ulule ») or external specialized pages, like Cwowd. In addition, inside the platform, rational herding could also come from specific comments directly posted on the platform (Hornuf and Schwienbacher 2018; Wang et al. 2018). Data provided by Ulule do not allow us to test this hypothesis, but this could be an interesting avenue for future research.

Another possible limit is that the present study is only focussed on RBCF, whereas Bessière et al. (2020) show, for instance, that the success of a RBCF campaign can be the kick-off event of a complex funding trajectory that continues with ECF and other actors of the market of entrepreneurial finance in successive funding rounds. Angel investors and venture capitalists become for example active on ECF platforms (Wang et al. 2019) and ICOs may interact with crowdfunding platforms (Block et al. 2020). Hence, future research could investigate if and to what extent information-cascades in RBCF have spill-over effects for other funding categories of a complex entrepreneurial project.

Acknowledgements $\mathrm{We}$ are indebted to participants at the ENTFIN 2019 conference in Trier and at the EU-SPRI 2019 workshop in Torino, especially Alexander Groh, Silvio Vismara and Vincenzo Buttice, as well as two anonymous referees for helpful comments and suggestions. We also thank Philipp Ketz for econometric advice, as well as Arnaud and Romain Burgot from Ulule for providing us the data and devoting time to answer our questions. We acknowledge financial support from the $\mathrm{Au}-$ vergne-Rhône-Alpes region (AURA-PMI program) and from the French Ministry DEPS/Labex ICCA (research grant on "Crowdfunding in Arts, Culture, and the Media"). Any remaining errors are our own. 


\section{Appendix}

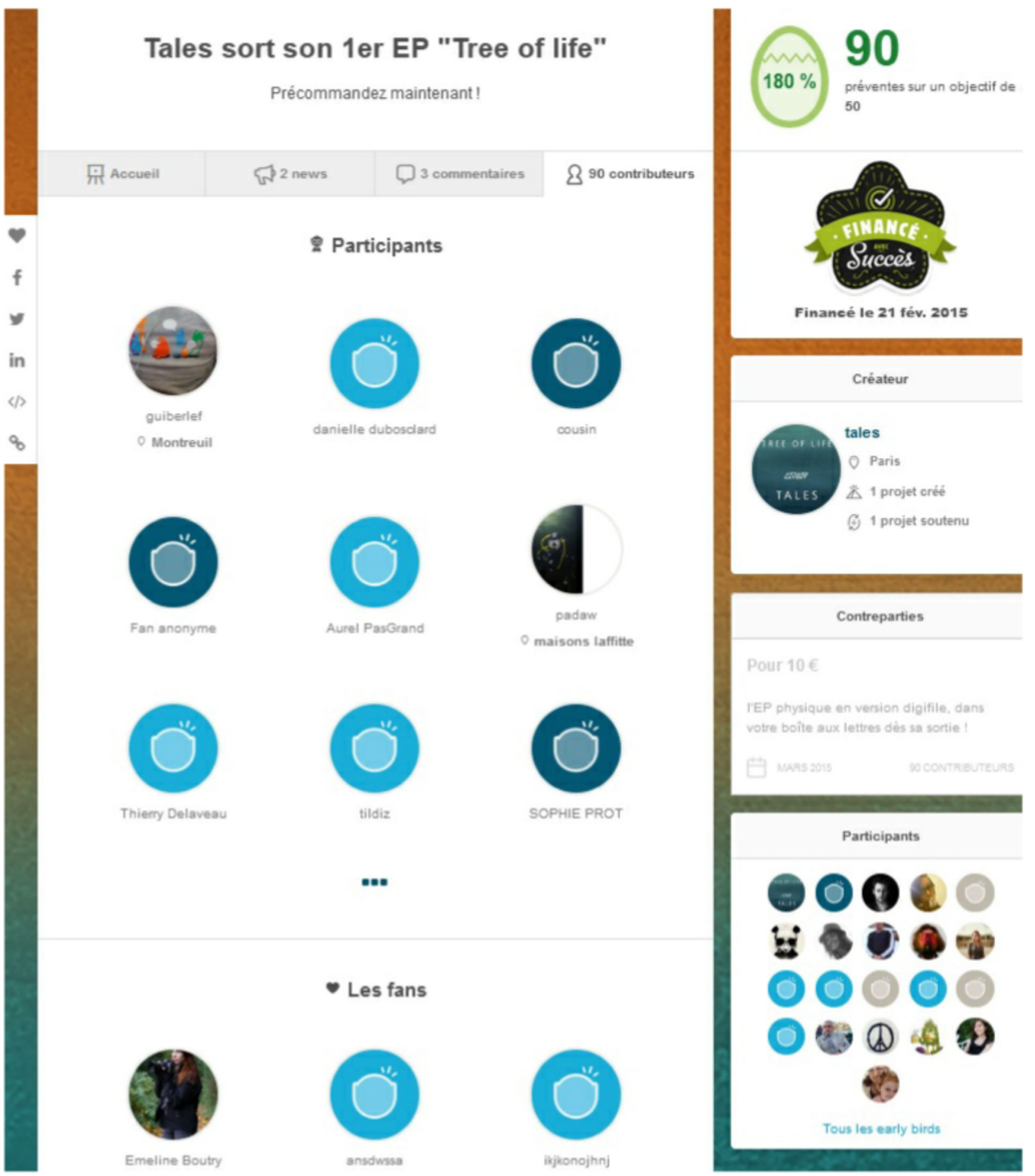

Fig. 1 Example of a project page (tab backers) on Ulule 
Fig. 2 Monthly number of contributions for different types of backers

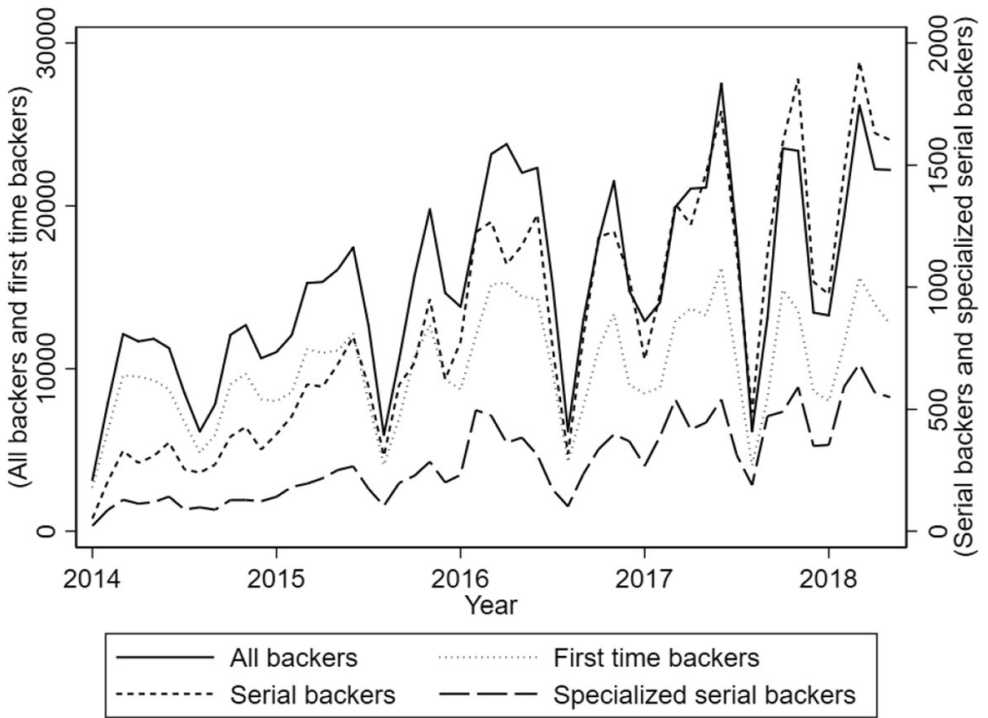

Table 7 Descriptive statistics of the static samples of projects used to test the robustness of the certification effect

\begin{tabular}{|c|c|c|c|c|}
\hline Variable & Mean & Std. err. & Min & Max \\
\hline \multicolumn{5}{|c|}{ Projects in categories Games, Comics, Video, Music and Journalism (6763 projects) used in Tables 10, 11 and 12.} \\
\hline Goal raised & 0.93 & 0.25 & 0 & 1 \\
\hline \multicolumn{5}{|c|}{ No. of contributions after the first 21 made by: } \\
\hline All backers & 70.53 & 196.69 & 1 & 7792 \\
\hline Senior experts & 10.04 & 31.61 & 0 & 701 \\
\hline Specialized senior experts & 4.33 & 15.38 & 0 & 349 \\
\hline Junior experts & 5.95 & 24.75 & 0 & 851 \\
\hline Specialized junior experts & 3.13 & 12.07 & 0 & 367 \\
\hline First-circle backers & 42.66 & 116.30 & 0 & 5024 \\
\hline \multicolumn{5}{|c|}{ No. of contributions in the first 21 made by: } \\
\hline Senior experts & 2.53 & 3.09 & 0 & 21 \\
\hline Specialized senior experts & 1.23 & 2.36 & 0 & 21 \\
\hline First-time backers & 15.74 & 4.16 & 0 & 21 \\
\hline
\end{tabular}

Data: Ulule, January 2014-June 2018. Only projects with more than 21 contributions are included 
Table 8 Descriptive statistics of the dynamic panels used to test the herding effect (for robustness tests in categories Games, Comics, Journalism, Video and Music)

\begin{tabular}{|c|c|c|c|c|c|}
\hline Variable & Obs & Mean & Std. Dev. & Min & Max \\
\hline \multicolumn{6}{|c|}{ Projects with funding duration of 46 days in categories Games, Comics, Video, Music and Journalism (685 projects) used in Table 13} \\
\hline \multicolumn{6}{|l|}{ Daily number of contributions by project made by: } \\
\hline All backers & 28770 & 1.987 & 5.298 & 0 & 284 \\
\hline Senior experts & 28770 & 0.275 & 1.183 & 0 & 58 \\
\hline Specialized senior experts & 28770 & 0.121 & 0.554 & 0 & 22 \\
\hline Junior experts & 28770 & 0.148 & 0.768 & 0 & 56 \\
\hline Specialized junior experts & 28770 & 0.044 & 0.293 & 0 & 16 \\
\hline First-circle backers & 28770 & 1.240 & 3.196 & 0 & 144 \\
\hline \multicolumn{6}{|c|}{ Daily cumulated number of contributions by project made on $\mathrm{T}-1$ by: } \\
\hline First-time backers & 28770 & 46.084 & 102.886 & 0 & 2294 \\
\hline Senior experts & 28770 & 8.743 & 25.840 & 0 & 598 \\
\hline Specialized senior experts & 28770 & 3.956 & 11.309 & 0 & 187 \\
\hline \multicolumn{6}{|l|}{ Daily control variables on $\mathrm{T}-1$} \\
\hline No. projects on Ulule & 28770 & 1042.514 & 387.266 & 135 & 5080 \\
\hline No. projects in the category & 28770 & 5.458 & 4.584 & 0 & 30 \\
\hline Non-funded share (floored) of the funding goal & 28770 & 0.424 & 0.330 & 0 & 1 \\
\hline
\end{tabular}

Data: Ulule, January 2014-June 2018. Sample restricted to the 9 last deciles of a funding campaign duration and projects counting at least one contribution after the first decile of the campaign

Table 9 Descriptive statistics of the panels used to test the herding effect (for robustness tests based on duration models and random-effects probit regressions)

\begin{tabular}{llllll}
\hline Variable & Obs & Mean & Std. dev. & Min & Max \\
\hline
\end{tabular}

Projects in all categories except Charities, Education and Environment used in Tables 14, 15, 16, 17, 18, and 19

Dummy variables indicating the type of backer of the last contribution:

\begin{tabular}{|c|c|c|c|c|c|}
\hline Senior experts & 1017458 & 0.12 & 0.32 & 0 & 1 \\
\hline Specialized senior experts & 1017458 & 0.04 & 0.20 & 0 & 1 \\
\hline Junior experts & 1017458 & 0.07 & 0.26 & 0 & 1 \\
\hline Specialized junior experts & 1017458 & 0.02 & 0.14 & 0 & 1 \\
\hline First-circle backers & 1017458 & 0.65 & 0.48 & 0 & 1 \\
\hline First-time backers & 1017458 & 0.76 & 0.43 & 0 & 1 \\
\hline \multicolumn{6}{|c|}{ Number of contributions among the last 9 made by: } \\
\hline First-time backers & 870999 & 6.77 & 1.98 & 0 & 9 \\
\hline Senior experts & 870999 & 1.06 & 1.44 & 0 & 9 \\
\hline Specialized senior experts & 870999 & 0.39 & 0.95 & 0 & 9 \\
\hline \multicolumn{6}{|l|}{ Daily control variables on T-1 } \\
\hline No. seconds to last contribution & 999807 & 52677 & 140876 & 0 & 7576013 \\
\hline Avg. no. seconds to last 9 contrib. & 870999 & 224162 & 319506 & 1.22 & $1.25 \mathrm{E}+07$ \\
\hline
\end{tabular}

Data: Ulule, January 2014 - June 2018. Sample restricted to the 9 last deciles of a funding campaign duration and projects counting at least one contribution after the first decile of the campaign 
Table 10 Certification effect caused by the composition of "early birds", i.e. the 21 first backers, on the success probability and on the number of future backers of projects, in categories Games, Comics, Journalism, Video and Music

Goal raised ( 0 if the campaign failed, 1 if succeeded)

\section{(1)}

(2)

(3)
Number of all backers after the first 21

$$
\begin{aligned}
& 0.026^{* * *} \\
& (0.010)
\end{aligned}
$$

Specialized senior experts

Obs.

$P(F)$

$R^{2}$ (or pseudo)

0.122

$$
(0.007)
$$

(0.010)

6763

0

0.122

$0.047 * * *$
$(0.014)$
6763
0

0.123
(5)

$$
\begin{aligned}
& -4.553 * * * \\
& (0.756)
\end{aligned}
$$

(4)

$\begin{array}{ll}5.529 * * * & \\ (0.988) & \\ & \begin{array}{l}-4.211 * * * \\ (1.037)\end{array} \\ 6763 & 6763 \\ 0 & 0 \\ 0.148 & 0.144\end{array}$

This table presents results of probit models in columns (1) to (3), where the dependent variable is equal to 1 when the funding goal is raised, and results of OLS regressions in columns (4) to (6), where the number of future contributions made by all types of backers is the dependent variable. Each regression includes a constant term, category fixed effects, the logarithm of the project's goal, the month of project's start, the duration of the campaign, the number of ongoing campaigns on the platform at the start of the project and the number of ongoing campaigns

\begin{tabular}{|c|c|c|c|c|c|c|}
\hline & \multicolumn{2}{|c|}{ Senior experts } & \multicolumn{2}{|c|}{ Junior experts } & \multicolumn{2}{|c|}{ First-circle backers } \\
\hline & (1) & (2) & (3) & (4) & (5) & (6) \\
\hline \multicolumn{7}{|c|}{ No. backers among the first 21} \\
\hline $\begin{array}{r}\text { First-time } \\
\text { backers }\end{array}$ & $\begin{array}{c}-0.018 * * * \\
(0.000)\end{array}$ & & $\begin{array}{c}-0.004 * * * \\
(0.000)\end{array}$ & & $\begin{array}{l}0.030 * * * \\
(0.001)\end{array}$ & \\
\hline $\begin{array}{l}\text { Senior } \\
\text { experts }\end{array}$ & & $\begin{array}{l}0.028 * * * \\
(0.001)\end{array}$ & & $\begin{array}{l}0.004 * * * \\
(0.000)\end{array}$ & & $\begin{array}{c}-0.038^{* * * *} \\
(0.001)\end{array}$ \\
\hline Obs. & 6763 & 6763 & 6763 & 6763 & 6763 & 6763 \\
\hline$F$ statistic & 145.4 & 219.2 & 27.27 & 23.03 & 288.2 & 237.3 \\
\hline$R^{2}$ & 0.450 & 0.500 & 0.103 & 0.0888 & 0.426 & 0.376 \\
\hline
\end{tabular}
in the same category at the start of the project. Data: Ulule, January 2014 to June 2018. Only projects with more than 21 contributions are included. *, ** and $* * *$ indicate significance levels at respectively $10 \%, 5 \%$ and $1 \% . R^{2}$ is a pseudo- $R^{2}$ for probit regressions

Table 11 Certification effect caused by the composition of "early birds", i.e. the 21 first backers, on the composition of future backers, in categories Games, Comics, Journalism, Video and Music: main types of backers

Shares of the contributions after the first 21 made by:

No. backers among the first 21

This table presents results of OLS regressions where the share of future contributions made by different types of backers is the dependent variable. Each regression includes a constant term, category fixed effects, the logarithm of the project's goal, the month of project's start, the duration of the campaign, the number of ongoing campaigns on the platform at the start of the project and the number of ongoing campaigns in the same category at the start of the project. Data: Ulule, January 2014 to June 2018. Only projects with more than 21 contributions are included. $*, * *$ and $* * *$ indicate significance levels at respectively $10 \%, 5 \%$ and $1 \%$ 
Table 12 Certification effect caused by the composition of "early birds", i.e. the 21 first backers, on the composition of future backers, in categories Games, Comics, Journalism, Video and Music: specialized senior and junior experts

Shares of the contributions after the first 21 made by:

Specialized senior experts $\quad$ Specialized junior experts

(1) (2) (3)

(3) (4)

No. of backers among the first 21

First-time backers

$-0.011 * * *$

(0.000)

Specialized senior experts

Obs.

$F$ statistic

$R^{2}$

60.18

0.361
$-0.006 * * *$

(0.000)

$\begin{array}{lll}0.028 * * * & & 0.009 * * * \\ (0.001) & & (0.001) \\ 6763 & 6763 & 6763 \\ 115.2 & 19.85 & 17.20 \\ 0.496 & 0.105 & 0.0852\end{array}$

This table presents results of OLS regressions where the share of future contributions made by different types of backers is the dependent variable. Each regression includes a constant term, category fixed effects, the logarithm of the project's goal, the month of project's start, the duration of the campaign, the number of ongoing campaigns on the platform at the start of the project and the number of ongoing campaigns in the same category at the start of the project. Data: Ulule, January 2014 to June 2018. Only projects with more than 21 contributions are included. * ** and $* * *$ indicate significance levels at respectively $10 \%, 5 \%$ and $1 \%$

Table 13 Herding effect of daily contributions in categories Games, Comics, Journalism, Video and Music

No. of daily contributions to a project made by:

\begin{tabular}{llllll}
\hline All & Senior & Specialized senior & Junior & Specialized junior & First-circle \\
backers & experts & experts & experts & experts & backers \\
$(1)$ & $(2)$ & $(3)$ & $(4)$ & $(5)$ & $(6)$
\end{tabular}

\begin{tabular}{|c|c|c|c|c|c|c|}
\hline First-time backers & $\begin{array}{r}0.00622^{*} \\
(0.00319)\end{array}$ & $\begin{array}{r}-0.00153^{* *} \\
(0.000653)\end{array}$ & $\begin{array}{r}-0.000324 * \\
(0.000174)\end{array}$ & $\begin{array}{r}-0.000151 \\
(0.000286)\end{array}$ & $\begin{array}{r}-6.16 \mathrm{e}-05 \\
(0.000104)\end{array}$ & $\begin{array}{l}0.00548 * * * \\
(0.00188)\end{array}$ \\
\hline Senior experts & $\begin{array}{r}0.00761 \\
(0.0142)\end{array}$ & $\begin{array}{l}0.0124 * * * \\
(0.00284)\end{array}$ & & $\begin{array}{c}0.00128 \\
(0.00121)\end{array}$ & & $\begin{array}{l}-0.0125 \\
(0.00815)\end{array}$ \\
\hline Specialized senior experts & & & $\begin{array}{l}0.0113 * * * \\
(0.00168)\end{array}$ & & $\begin{array}{l}0.00332 * * * \\
(0.00125)\end{array}$ & \\
\hline $\begin{array}{l}\text { Lag } 1 \text { of the dependent } \\
\text { variable }\end{array}$ & $\begin{array}{l}0.644 * * * \\
(0.0915)\end{array}$ & $\begin{array}{l}0.613 * * * \\
(0.144)\end{array}$ & $\begin{array}{l}0.611 * * * \\
(0.0780)\end{array}$ & $\begin{array}{l}0.980 * * * \\
(0.214)\end{array}$ & $\begin{array}{l}0.770 * * * \\
(0.154)\end{array}$ & $\begin{array}{l}0.807 * * * \\
(0.134)\end{array}$ \\
\hline Observations & 28085 & 28085 & 28085 & 28085 & 28085 & 28085 \\
\hline No. of groups (projects) & 685 & 685 & 685 & 685 & 685 & 685 \\
\hline No. of instruments & 667 & 676 & 676 & 684 & 684 & 684 \\
\hline $\mathrm{P}($ Hansen $)$ & 0.199 & 0.247 & 0.249 & 0.323 & 0.324 & 0.342 \\
\hline $\mathrm{P}(\mathrm{z}(\mathrm{AR} 1))$ & 0.0161 & 0.000307 & $3.05 \mathrm{e}-09$ & $2.50 \mathrm{e}-05$ & $1.01 \mathrm{e}^{-07}$ & 0.00188 \\
\hline $\mathrm{P}(\mathrm{z}(\mathrm{AR} 2))$ & 0.105 & 0.0204 & $9.84 \mathrm{e}-06$ & 0.00182 & 0.000422 & 0.0619 \\
\hline $\mathrm{P}(\mathrm{z}(\mathrm{AR} 3))$ & 0.551 & 0.919 & 0.811 & 0.353 & 0.575 & 0.956 \\
\hline$P(F)$ & 0 & 0 & 0 & 0 & 0 & 0 \\
\hline
\end{tabular}

All linear dynamic panel regressions (with lagged levels used as instruments starting at 3) include the share of the further amount to be funded (between 0 , when the funding goal is raised, and 1) on day - 1, dummy variables for each decile of a campaign and for the last day of campaign, as well as the number of ongoing projects on the platform or more specifically on the category and a constant term. Variables of interest are considered as endogenous. $\mathrm{P}(\mathrm{z})$ indicates the $p$ value of the Arrelano-Bond test for $\mathrm{AR}(1), \mathrm{AR}(2)$ and $\mathrm{AR}(3)$ in first differences. Data: Ulule, January 2014 to June 2018. Sample restricted to the 9 last deciles of a funding campaign duration, projects counting at least one contribution after the first decile of the campaign and to funding campaigns of 46 days. *, ** and *** indicate significance levels at respectively $10 \%, 5 \%$ and $1 \%$ 
Table 14 Herding effect of contributions in all categories except Charities, Education and Environment, robustness tests with duration analysis: impact of the last backer on the frequency of contribution

Average failure rate to the last contribution:

\begin{tabular}{|c|c|c|c|c|c|}
\hline \multicolumn{2}{|l|}{ All backers } & \multicolumn{2}{|c|}{ Senior experts } & \multicolumn{2}{|c|}{ Junior experts } \\
\hline (1) & (2) & (3) & (4) & (5) & (6) \\
\hline \multicolumn{6}{|l|}{ ontribution: } \\
\hline \multirow[t]{2}{*}{$\begin{array}{c}-0.161 * * * \\
(0.00899)\end{array}$} & & $\begin{array}{c}-0.737 * * * \\
(0.0215)\end{array}$ & & $\begin{array}{c}-0.314 * * * \\
(0.0217)\end{array}$ & \\
\hline & $\begin{array}{l}0.192 * * * \\
(0.0120)\end{array}$ & & $\begin{array}{l}0.928 * * * \\
(0.0262)\end{array}$ & & $\begin{array}{l}0.277 * * * \\
(0.0266)\end{array}$ \\
\hline 776172 & 776172 & 91442 & 91442 & 56778 & 56778 \\
\hline 10493 & 10459 & 3522 & 3797 & 2047 & 1963 \\
\hline 0.0363 & 0.0352 & 0.0425 & 0.0430 & 0.0374 & 0.0368 \\
\hline
\end{tabular}

Type of the backer of the last contribution:

First-time backers

Senior experts

Obs.

$\chi^{2}$

Pseudo- $R^{2}$

0.0363

$-0.737 * * *$
$(0.0215)$
Specialized senior experts

(9)
(10)
(8)

First-circle backers
(7)

Type of the backer of the last contribution:

First-time backers

$$
\begin{aligned}
& 0.0797 * * * \\
& (0.00864)
\end{aligned}
$$

Senior experts

Specialized senior experts

$\begin{array}{ll}\text { Obs. } & 517236 \\ \chi^{2} & 9723 \\ \text { Pseudo- } R^{2} & 0.0357\end{array}$

$-0.725 * * *$

(0.0304)

$-0.0923 * * *$

(0.0119)

0.0357

$\begin{array}{lc} & -0.725 * * * \\ & (0.0304) \\ -0.0923 * * * & \\ (0.0119) & \end{array}$

17236

9520

0.0357
Specialized junior experts

(11)

(12)

This table presents results of Cox proportional hazard regressions where the dependent variable (the failure rate) is inversely proportional to the time elapsed since the average time since the last nine contributions. A positive coefficient indicates for example that the average time to the next contribution decreases. All regressions include the share of the further amount to be funded (between 0 , when the funding goal is raised, and 1) after the last contribution, dummy variables for each decile of a campaign and for the last day of campaign, as well as the number of ongoing projects on the platform or more specifically on the category and a constant term. Data: Ulule, January 2014 to June 2018. Sample restricted to the 9 last deciles of a funding campaign duration and projects counting at least one contribution after the first decile of the campaign. $*$, ** and $* * *$ indicate significance levels at respectively $10 \%, 5 \%$ and $1 \%$ 
Table 15 Herding effect of contributions in all categories except Charities, Education and Environment, robustness tests with duration analysis: impact of the composition of the last 9 backers on the frequency of contribution

Average failure rate to the last 9 contributions:

\begin{tabular}{lll}
\hline All backers & Senior experts & Junior experts \\
\hline
\end{tabular}

(2)

(3)

(4)

(5)

(6)

\begin{tabular}{|c|c|c|c|c|c|c|}
\hline \multicolumn{7}{|l|}{ No. among the last 9 backers } \\
\hline First-time backers & \multirow[t]{2}{*}{$\begin{array}{c}-0.0986^{* * * *} \\
(0.00480)\end{array}$} & & \multicolumn{2}{|l|}{$\begin{array}{r}-0.333 * * * \\
(0.00695)\end{array}$} & \multirow[t]{2}{*}{$\begin{array}{r}-0.169 * * * \\
(0.00850)\end{array}$} & \\
\hline Senior experts & & $\begin{array}{c}0.126 * * * \\
(0.00655)\end{array}$ & & $\begin{array}{c}0.398 * * * \\
(0.00784)\end{array}$ & & $\begin{array}{l}0.176 * * * \\
(0.0102)\end{array}$ \\
\hline Obs. & 762374 & 762374 & 89118 & 89118 & 54991 & 54991 \\
\hline$\chi^{2}$ & 4524 & 4546 & 5155 & 5588 & 2215 & 1908 \\
\hline \multirow[t]{3}{*}{ Pseudo- $R^{2}$} & 0.0516 & 0.0513 & 0.0723 & 0.0732 & 0.0527 & 0.0501 \\
\hline & \multicolumn{2}{|c|}{ First-circle backers } & \multicolumn{2}{|c|}{ Specialized senior experts } & \multicolumn{2}{|c|}{ Specialized junior experts } \\
\hline & (7) & $(8)$ & (9) & $(10)$ & (11) & (12) \\
\hline \multicolumn{7}{|l|}{ No. among the last 9 backers } \\
\hline First-time backers & $\begin{array}{l}0.0184 * * * \\
(0.00463)\end{array}$ & & $\begin{array}{r}-0.338 * * * \\
(0.00988)\end{array}$ & & $\begin{array}{c}-0.174 * * * \\
(0.0127)\end{array}$ & \\
\hline Senior experts & & $\begin{array}{c}-0.0261 * * * \\
(0.00660)\end{array}$ & & & & \\
\hline Specialized senior experts & & & & $\begin{array}{l}0.442 * * * \\
(0.0120)\end{array}$ & & $\begin{array}{l}0.195 * * * \\
(0.0159)\end{array}$ \\
\hline Obs. & 498502 & 498502 & 32055 & 32055 & 14273 & 14273 \\
\hline$\chi^{2}$ & 3366 & 3339 & 2125 & 2468 & 871.8 & 758.6 \\
\hline Pseudo- $R^{2}$ & 0.0475 & 0.0475 & 0.0671 & 0.0691 & 0.0431 & 0.0388 \\
\hline
\end{tabular}

This table presents results of Cox proportional hazard regressions where the dependent variable (the failure rate) is inversely proportional to the time elapsed since the average time since the last nine contributions. A positive coefficient indicates for example that the average time to the next contribution decreases. All regressions include the share of the further amount to be funded (between 0 , when the funding goal is raised, and 1) after the last contribution, dummy variables for each decile of a campaign and for the last day of campaign, as well as the number of ongoing projects on the platform or more specifically on the category and a constant term. Data: Ulule, January 2014 to June 2018. Sample restricted to the 9 last deciles of a funding campaign duration and projects counting at least one contribution after the first decile of the campaign. $*$, ** and $* * *$ indicate significance levels at respectively $10 \%, 5 \%$ and $1 \%$ 
Table 16 Herding effect of contributions in all categories except Charities, Education and Environment, robustness tests with randomeffects probit regressions: impact of the last backer on the probability of contribution, main types of backers

Probability that a contribution is made by:

\begin{tabular}{|c|c|c|c|c|c|}
\hline $\begin{array}{l}\text { Senior experts } \\
\text { (1) }\end{array}$ & $\begin{array}{l}\text { Senior experts } \\
\text { (2) }\end{array}$ & $\begin{array}{l}\text { Junior experts } \\
\text { (3) }\end{array}$ & $\begin{array}{l}\text { Junior experts } \\
\text { (4) }\end{array}$ & $\begin{array}{l}\text { First-circle backers } \\
\text { (5) }\end{array}$ & $\begin{array}{l}\text { First-circle backers } \\
\text { (6) }\end{array}$ \\
\hline
\end{tabular}

\begin{tabular}{|c|c|c|c|c|c|c|}
\hline First-time backers & $\begin{array}{c}-0.115 * * * \\
(0.00462)\end{array}$ & & $\begin{array}{c}-0.0659 * * * \\
(0.00541)\end{array}$ & & $\begin{array}{l}0.0889 * * * \\
(0.00373)\end{array}$ & \\
\hline Senior experts & & $\begin{array}{l}0.0970 * * * \\
(0.00574)\end{array}$ & & $\begin{array}{l}0.0734 * * * \\
(0.00705)\end{array}$ & & $\begin{array}{r}-0.105^{* * *} * \\
(0.00495)\end{array}$ \\
\hline Observations & 811886 & 811886 & 811886 & 811886 & 811886 & 811886 \\
\hline No. of groups (projects) & 16950 & 16950 & 16950 & 16950 & 16950 & 16950 \\
\hline$P(F)$ & 0 & 0 & 0 & 0 & 0 & 0 \\
\hline$\chi^{2}$ & 924.3 & 591.4 & 424.1 & 384.0 & 758.7 & 645.5 \\
\hline
\end{tabular}

All random-effects probit regressions include the share of the further amount to be funded (between 0, when the funding goal is raised, and 1 ) after the last contribution, dummy variables for each decile of a campaign and for the last day of campaign, as well as the number of ongoing projects on the platform or more specifically on the category and a constant term. Data: Ulule, January 2014 to June 2018. Sample restricted to the 9 last deciles of a funding campaign duration and projects counting at least one contribution after the first decile of the campaign. *,** and $* * *$ indicate significance levels at respectively $10 \%, 5 \%$ and $1 \%$

Table 17 Herding effect of contributions in all categories except Charities, Education and Environment, robustness tests with randomeffects probit regressions: impact of the last backer on the probability of contribution, specialized senior and junior experts

Probability that a contribution is made by:

Specialized senior experts Specialized senior experts Specialized junior experts Specialized junior experts (1) (2) (3) (4)

Type of the backer of the last contribution:

$\begin{array}{lr}\text { First-time backers } \quad-0.105 * * * \\ & (0.00664) \\ \text { Specialized senior experts } & \end{array}$

Observations

No.of groups (projects)

$P(F)$

$\chi^{2}$

$$
\begin{gathered}
-0.0745 * * * \\
(0.00896)
\end{gathered}
$$

$0.0879 * * *$
$(0.0104)$
811886
16950
0
256.6

$\begin{array}{ll}811886 & 811886 \\ 16950 & 16950 \\ 0 & 0 \\ 436.8 & 256.6\end{array}$

811886
16950
0

218.2
$0.126^{* * * *}$

(0.0153)

811886

16950

0

217.0

All random-effects probit regressions include the share of the further amount to be funded (between 0, when the funding goal is raised, and 1) after the last contribution, dummy variables for each decile of a campaign and for the last day of campaign, as well as the number of ongoing projects on the platform or more specifically on the category and a constant term. Data: Ulule, January 2014 to June 2018. Sample restricted to the 9 last deciles of a funding campaign duration and projects counting at least one contribution after the first decile of the campaign. $*, * *$ and $* * *$ indicate significance levels at respectively $10 \%, 5 \%$ and $1 \%$ 
Table 18 Herding effect of contributions in all categories except Charities, Education and Environment, robustness tests with randomeffects probit regressions: impact of the composition of the last 9 backers on the probability of contribution, main types of backers

Probability that a contribution is made by:

\begin{tabular}{|c|c|c|c|c|c|}
\hline $\begin{array}{l}\text { Senior experts } \\
\text { (1) }\end{array}$ & $\begin{array}{l}\text { Senior experts } \\
\text { (2) }\end{array}$ & $\begin{array}{l}\text { Junior experts } \\
\text { (3) }\end{array}$ & $\begin{array}{l}\text { Junior Experts } \\
\text { (4) }\end{array}$ & $\begin{array}{l}\text { First-circle backers } \\
\text { (5) }\end{array}$ & $\begin{array}{l}\text { First-circle backers } \\
\text { (6) }\end{array}$ \\
\hline
\end{tabular}

No. among the last 9 backers:

$$
\begin{array}{ll}
\text { First-time backers } \quad-0.0856^{* * * *} \\
(0.00154)
\end{array}
$$

Senior experts

\section{Observations}

763900

No. of groups (projects)

14621

$P(F)$

$\chi^{2}$

3334
(3)
$0.0623 * * *$

(0.00125)

$0.0536 * * *$
$(0.00216)$

763900

14621

0

$0 \quad 0$

1876
14621

0

852.4

763900
14621
0
2588

$-0.0789 * * *$
$(0.00165)$
763900
14621
0
2393

All random-effects probit regressions include the share of the further amount to be funded (between 0, when the funding goal is raised, and 1) after the last contribution, dummy variables for each decile of a campaign and for the last day of campaign, as well as the number of ongoing projects on the platform or more specifically on the category and a constant term. Data: Ulule, January 2014 to June 2018. Sample restricted to the 9 last deciles of a funding campaign duration and projects counting at least one contribution after the first decile of the campaign. *,** and $* * *$ indicate significance levels at respectively $10 \%, 5 \%$ and $1 \%$

Table 19 Herding effect of contributions in all categories except Charities, Education and Environment, robustness tests with random-effects probit regressions: impact of the composition of the last 9 backers on the probability of contribution: specialized senior and junior experts

Probability that a contribution is made by:

Specialized senior experts Specialized senior experts Specialized junior experts Specialized junior experts

(1)

No. among the last 9 backers:

$\begin{array}{cc}\text { First-time backers } & -0.0750 * * * \\ & (0.00212)\end{array}$

Specialized senior experts

Observations

763900

No. of groups (projects)

14621

$P(F)$

$\chi^{2}$

0

1397
(2)

(3)

0.0770 ***
$(0.00379)$
763900
14621
0
558.1

558.1
(4)

$$
-0.0467 * * *
$$$$
\text { (0.00264) }
$$

$\begin{array}{ll} & 0.0995 * * * \\ & (0.00480) \\ 763900 & 763900 \\ 14621 & 14621 \\ 0 & 0 \\ 423.1 & 541.1\end{array}$

All random-effects probit regressions include the share of the further amount to be funded (between 0, when the funding goal is raised, and 1 ) after the last contribution, dummy variables for each decile of a campaign and for the last day of campaign, as well as the number of ongoing projects on the platform or more specifically on the category and a constant term. Data: Ulule, January 2014 to June 2018. Sample restricted to the 9 last deciles of a funding campaign duration and projects counting at least one contribution after the first decile of the campaign. *,** and $* * *$ indicate significance levels at respectively $10 \%, 5 \%$ and $1 \%$ 
Open Access This article is licensed under a Creative Commons Attribution 4.0 International License, which permits use, sharing, adaptation, distribution and reproduction in any medium or format, as long as you give appropriate credit to the original author(s) and the source, provide a link to the Creative Commons licence, and indicate if changes were made. The images or other third party material in this article are included in the article's Creative Commons licence, unless indicated otherwise in a credit line to the material. If material is not included in the article's Creative Commons licence and your intended use is not permitted by statutory regulation or exceeds the permitted use, you will need to obtain permission directly from the copyright holder. To view a copy of this licence, visit http://creativecommons.org/licenses/by/4.0/.

\section{References}

Agrawal, A., Catalini, C., \& Goldfarb, A. (2014). Some simple economics of crowdfunding. Innovation Policy and the Economy, 14(1), 63-97.

Agrawal, A., Catalini, C., \& Goldfarb, A. (2015). Crowdfunding: Geography, social networks, and the timing of investment decisions. Journal ofEconomics \& Management Strategy, 24(2), 253-274

Alegre, I., \& Moleskis, M. (2019). Beyond financial motivations in Crowdfunding: A systematic literature review of donations and rewards. VOLUNTAS: International Journal of Voluntary and Nonprofit Organizations. https://doi. org/10.1007/s11266-019-00173-w.

André, K., Bureau, S., Gautier, A., \& Rubel, O. (2017). Beyond the opposition between altruism and self-interest: Reciprocal giving in reward-based crowdfunding. Journal of Business Ethics, 146(2), 313-332.

Aral, S., Muchnik, L., \& Sundararajan, A. (2009). Distinguishing influence-based contagion from homophily-driven diffusion in dynamic networks. Proceedings of the National Academy of Sciences, 106(51), 21544-21549.

Belleflamme, P., Lambert, T., Schwienbacher, A. (2019). Crowdfunding Dynamics, CESifo Working Paper, No. 7797, Center for Economic Studies andifoInstitute (CESifo), Munich.

Berkovich, E. (2011). Search and herding effects in peer-to-peer lending: Evidence from prosper.com. Annals of Finance, 7(3), 389-405.

Bernard, A. \& Gazel, M. (2018). Les financeurs participatifs et l'industrie financent-ils les mêmes projets?, in Financement participatif : une voie d'avenir pour la culture? (pp 105127). French Ministry of Culture and Presses de Sciences Po.

Bessière, V., Stéphany, E., \& Wirtz, P. (2020). Crowdfunding, business angels, and venture capital: An exploratory study of the concept of the funding trajectory. Venture Capital, 22(2), $135-160$.

Bikhchandani, S., Hirshleifer, D., \& Welch, I. (1992). A theory of fads, fashion, custom, and cultural change as informational cascades. Journal of Political Economy, 100(5), 992-1026.

Block, J. H., Colombo, M. G., Cumming, D. J., \& Vismara, S. (2018). New players in entrepreneurial finance and why they are there. Small Business Economics, 50(2), 239-250.
Block, J. H., Groh, A., Hornuf, L., Vanacker, T., \& Vismara, S. (2020). The entrepreneurial finance markets of the future: A comparison of crowdfunding and initial coin offerings. Small Business Economics. https://doi.org/10.1007/s11187-02000330-2.

Bretschneider, U., \& Leimeister, J. M. (2017). Not just an ego-trip: Exploring backers' motivation for funding in incentive-based crowdfunding. The Journal of Strategic Information Systems, 26(4), 246-260.

Burtch, G., Ghose, A., \& Wattal, S. (2013). An empirical examination of the antecedents and consequences of contribution patterns in crowd-funded markets. Information Systems Research, 24(3), 499-519.

Caves, R. E. (2003). Contracts between art and commerce. Journal of Economic Perspectives, 17(2), 73-83.

Chan, H. F., Moy, N., Schaffner, M., \& Torgler, B. (2019). The effects of money saliency and sustainability orientation on reward based crowdfunding success. Journal of Business Research. https://doi.org/10.1016/j.jbusres.2019.07.037.

Chan, C. R., Parhankangas, A., Sahaym, A., \& Oo, P. (2020). Bellwether and the herd? Unpacking the u-shaped relationship between prior funding and subsequent contributions in reward-based crowdfunding. Journal of Business Venturing, 35(2), 105934

Chan, C. R., Park, H. D., Patel, P., \& Gomulya, D. (2018). Reward-based crowdfunding success: Decomposition of the project, product category, entrepreneur, and location effects. Venture Capital, 20(3), 285-307.

Cholakova, M., \& Clarysse, B. (2015). Does the possibility to make equity investments in crowdfunding projects crowd out reward-based investments? Entrepreneurship Theory and Practice, 39(1), 145-172.

Colombo, M. G., Franzoni, C., \& Rossi-Lamastra, C. (2015). Internal social capital and the attraction of early contributions in crowdfunding. Entrepreneurship Theory and Practice, 39(1), 75-100.

Crosetto, P., \& Regner, T. (2018). It's never too late: Funding dynamics and self pledges in reward-based crowdfunding. Research Policy, 47(8), 1463-1477.

Dai, H., \& Zhang, D. J. (2019). Prosocial goal pursuit in crowdfunding: Evidence from kickstarter. Journal of Marketing Research, 56(3), 498-517.

Dahlin, L., Clark, J., \& Rhue, L. (2019). Crowdfunding community formation: Fundraiser race and gender homophily. Working Paper. Retrieved onNovember 7, 2020, from http://laurendahlin.com/pdfs/dahlin_rhue_clark crowdfunding community march 2019.pdf.

de Witt, N. (2012). A Kickstarter's guide to kickstarter. Retrieved on November 7, 2020, from http://kickstarterguide. com/files/2012/07/AKickstarters-Guide.pdf.

Devenow, A., \& Welch, I. (1996). Rational herding in financial economics. European Economic Review, 40, 603-615.

Fisher, G., Kuratko, D. F., Bloodgood, J. M., \& Hornsby, J. S. (2017). Legitimate to whom? The challenge of audience diversity and new venture legitimacy. Journal of Business Venturing, 32(1), 52-71.

Frydrych, D., Bock, A., Kinder, T., \& Koeck, B. (2014). Exploring entrepreneurial legitimacy in reward-based crowdfunding. Venture Capital, 16(3), 247-269. https://doi. org/10.1080/13691066.2014.916512. 
Gerber, E. M., \& Hui, J. (2013). Crowdfunding: Motivations and deterrents for participation. ACM Transactions on ComputerHuman Interaction (TOCHI), 20(6), 1-32.

Giudici, G., Guerini, M., \& Rossi-Lamastra, C. (2018). Rewardbased crowdfunding of entrepreneurial projects: The effect of local altruism and localized social capital on proponents' success. Small Business Economics, 50(2), 307-324.

Greenberg, J., \& Mollick, E. (2017). Activist choice homophily and the crowdfunding of female founders. Administrative Science Quarterly, 62(2), 341-374.

Hahn, J., \& Lee, G. (2013). Archetypes of crowdfunders' backing behaviors and the outcome of crowdfunding efforts: An exploratory analysis of kickstarter. Conference on information systems and technology, March 9-10, Mathura.

Herzenstein, M., Dholakia, U., \& Andrews, R. (2011). Strategic herding behaviors in peer-to-peer loan auctions. Journal of Interactive Marketing, 25(1), 27-36.

Hornuf, L., \& Schwienbacher, A. (2018). Market mechanisms and funding dynamics in equity crowdfunding. Journal of Corporate Finance, 50, 556-574.

Hung, A. A., \& Plott, C. R. (2001). Information cascades: Replication and an extension to majority rule and conformity-rewarding institutions. American Economic Review, 91(5), 1508-1520.

Kang, L., Jiang, Q., \& Tan, H. (2017). Remarkable advocates: An investigation of geographic distance and social capital for crowdfunding. Information \& Management, 54, 336-348.

Kim, H. W., \& Gupta, S. (2009). A comparison of purchase decision calculus between potential and repeat customers of an online store. Decision Support Systems, 47, 477-487.

Kim, K., \& Viswanathan, S. (2018). The 'experts' in the crowd: The role of experienced investors in a crowdfunding market. Mis Quarterly.

Kshetri, N. (2015). Success of crowd-based online technology in fundraising: An institutional perspective. Journal of International Management, 21(2), 100-116.

Kuppuswamy, V., \& Bayus, B. L. (2017). Does my contribution to your crowdfunding project matter? Journal of Business Venturing, 32(1), 72-89.

Kuppuswamy, V., \& Bayus, B. L. (2018). Crowdfunding creative ideas: The dynamics of project backers. In D. Cumming \& L. Hornuf (Eds.), The economics of crowdfunding. Cham: Palgrave Macmillan.

Lin, Y., Boh, W. F., \& Goh, K. H. (2014). How different are crowdfunders? Examining archetypes of crowdfunders and their choice of projects. In Academy of Management Proceedings (pp 14-1, 3309). Briarcliff Manor, NY: Academy of Management.

Lumeau, M., Mahé, F., \& Viotto da Cruz, J. (2018). Le financement participatif au défi de l'attention, in Financement participatif : une voie d'avenir pour la culture ? (pp. 73-101). French Ministry of Culture and Presses de Sciences Po.

McCain, R. A. (1995). Cultivation of taste and bounded rationality: Some computer simulations. Journal of Cultural Economics, 19(1), 1-15.
McPherson, M., Smith-Lovin, L., \& Cook, J. M. (2001). Birds of a feather: Homophily in social networks. Annual Review of Sociology, 27(1), 415-444.

Mochkabadi, K., \& Volkmann, C. K. (2020). Equity crowdfunding: A systematic review of the literature. Small Business Economics, 54(1), 75-118.

Mollick, E. (2014). The dynamics of crowdfunding: An exploratory study. Journal of Business Venturing, 29(1), 1-16.

Mollick, E. (2018). Crowdfunding as a font of entrepreneurship: Outcomes of reward-based crowdfunding. In D. Cumming, L. Hornuf (Eds.), The economics of crowdfunding (pp. 133150). Cham: Palgrave Macmillan.

Mollick, E., \& Nanda, R. (2015). Wisdom or madness? Comparing crowds with expert evaluation in funding the arts. Management Science, 62(6), 1533-1553.

Moritz, A., \& Block, J. H. (2016). Crowdfunding: A literature review and research directions. In D. Brüntje, O. Gajda (Eds.), Crowdfunding in Europe (pp. 25-53). Cham: Springer.

Nielsen, K. R., \& Binder, J. K. (2020). I am what i pledge: The importance of value alignment for mobilizing backers in reward-based crowdfunding. Entrepreneurship Theory and Practice. https://doi.org/10.1177/1042258720929888.

Ordanini, A., Miceli, L., Pizzetti, M., \& Parasuraman, A. (2011). Crowd-funding: Transforming customers into investors through innovative service platforms. Journal of Service Management, 22(4), 443-470.

Pavlou, A. (2003). Consumer acceptance of electronic commerce: Integrating trust and risk with the technology acceptance model. International Journal of Electronic Commerce, 7(3), 101-134.

Petit, A. (2018). Les multi-contributeurs des plateformes de financement participatif par don avec contrepartie). In Financement participatif : une voie d'avenir pour la culture ? (47-72). French Ministry of Culture and Presses de Sciences Po.

Pollack, J. M., Maula, M., Allison, T. H., Renko, M., \& Guenther, C. C. (2019). Making a contribution to entrepreneurship research by studying crowd-funded entrepreneurial opportunities. Entrepreneurship Theory and Practice. https://doi. org/10.1177/1042258719888640.

Polzin, F., Toxopeus, H., \& Stam, E. (2018). The wisdom of the crowd in funding: Information heterogeneity and social networks of crowdfunders. Small Business Economics, 50(2), 251-273.

Reinstein, D. A., \& Snyder, C. M. (2005). The influence of expert reviews on consumer demand for experience goods: A case study of movie critics. The Journal of Industrial Economics, 53(1), 27-51.

Ryu, S., \& Kim, Y. G. (2016). A typology of crowdfunding sponsors: Birds of a feather flock together? Electronic Commerce Research and Applications, 16, 43-54.

Signori, A., \& Vismara, S. (2018). Does success bring success? The post-offering lives of equity-crowdfunded firms. Journal of Corporate Finance, 50, 575-591. 
Solomon, J., Ma, W., \& Wash, R. (2015). Don’t wait!: How timing affects coordination of crowdfunding donations. In Proceedings of the 18th acm conference on computer supported cooperative work \& social computing (pp. 547-556). New York: ACM.

Thies, F., Wessel, M., \& Benlian, A. (2014). Understanding the dynamic interplay of social buzz and contribution behavior within and between online platforms-evidence from crowdfunding. Thirty Fifth International Conference on Information Systems, Auckland.

Thürridl, C., \& Kamleitner, B. (2016). What goes around comes around? Rewards as strategic assets in crowdfunding. California Management Review, 58(2), 88-110.

Vismara, S. (2016). Equity retention and social network theory in equity crowdfunding. Small Business Economics, 46(4), 579-590.

Vismara, S. (2018). Information cascades among investors in equity crowdfunding. Entrepreneurship Theory and Practice, 42(3), 467-497.

Vismara, S. (2019). Sustainability in equity crowdfunding. Technological Forecasting and Social Change, 141, 98-106.
Wallmeroth, J., Wirtz, P., \& Groh, A. P. (2018). Venture capital, angel financing, and crowdfunding of entrepreneurial ventures: A literature review. Foundations and Trends ${ }^{\circledR}$ in Entrepreneurship, 14(1), 1-129.

Wang, N., Li, Q., Liang, H., Ye, T., \& Ge, S. (2018). Understanding the importance of interaction between creators and backers in crowdfunding success. Electronic Commerce Research and Applications, 27, 106-117.

Wang, W., Mahmood, A., Sismeiro, C., \& Vulkan, N. (2019). The evolution of equity crowdfunding: Insights from coinvestments of angels and the crowd. Research Policy, 48(8), 103727.

Yang, L., \& Hahn, J. (2016). Learning from prior experience: an empirical study of serial entrepreneurs in IT-enabled crowdfunding. Available at SSRN 3006930.

Zhang, J., \& Liu, P. (2012). Rational herding in microloan markets. Management Science, 58(5), 892-912.

Publisher's note Springer Nature remains neutral with regard to jurisdictional claims in published maps and institutional affiliations. 